\title{
Paleomagnetismo y edad de la Ignimbrita Panalillo Superior, Campo Volcánico de San Luis Potosí, México
}

\author{
Gildardo A. González-Naranjo ${ }^{1, *}$, Roberto S. Molina-Garza ${ }^{2}$, José Jorge Aranda-Gómez², \\ Margarito Tristán-González ${ }^{3}$, Alfredo Aguillón-Róbles ${ }^{3}$, Alexander Iriondo ${ }^{2}$, Hervé Bellón ${ }^{4}$ \\ ${ }^{1}$ Posgrado Centro de Geociencias, Universidad Nacional Autónoma de México, Juriquilla, Querétaro. México. \\ ${ }^{2}$ Centro de Geociencias, Universidad Nacional Autónoma de México, Juriquilla, Qro. México. \\ ${ }^{3}$ Instituto de Geología, Universidad Autónoma de San Luis Potosí, San Luis Potosí, S.L.P., México. \\ ${ }^{4}$ UMR 6538, Domains Océaniques, IUEM, Université de Bretagne Occidentale, Brest, Cedex. France. \\ *gildardogonzalez332@hotmail.com
}

\begin{abstract}
Resumen
La Ignimbrita Panalillo Superior es una unidad litoestratigráfica formal del Oligoceno que aflora de manera esporádica en un área de $\sim 15,000 \mathrm{~km}^{2}$ en el Campo Volcánico de San Luis Potosí (CVSLP), en la parte sudoriental de la Mesa Central de México. Se realizó un muestreo para caracterizar su registro paleomagnético y edad isotópica en las zonas de afloramiento mejor expuestas y con mejor acceso. Los sitios fueron agrupados en 5 zonas de acuerdo a su distribución geográfica y características estructurales. Estas zonas son: Noroeste o La Pendencia (1), Norte o Valle Umbroso (2), Centro-Norte o Mexquitic (3), Este o Panalillo (4) y Sur o Graben de Bledos (5). En el estudio paleomagnético se obtuvieron paleopolos virtuales y direcciones medias para: 1) cada sitio de muestreo, 2) cada zona y 3) para todo el conjunto de muestras. Los paleopolos virtuales de la Ignimbrita Panalillo Superior se combinaron con otros paleopolos virtuales ya publicados de rocas de edad similar en el campo volcánico, para así obtener un paleopolo global para el CVSLP que es $72.1^{\circ} \mathrm{N}-165.5^{\circ} \mathrm{E}\left(\mathrm{N}=17, \mathrm{~K}=228.2\right.$, A95 $\left.=6.8^{\circ}\right)$. Este resultado se comparó con el paleopolo de referencia de Norteamérica y se determinó la posible rotación tectónica $(\mathrm{R})$ y desplazamiento latitudinal (F) que habría experimentado esta región. Para acotar la edad de emplazamiento de la Ignimbrita Panalillo Superior se emplearon siete fechamientos isotópicos, tres de ${ }^{40} \mathrm{Ar} /{ }^{39} \mathrm{Ar}$ por la técnica de fusión LASER de cristales individuales de sanidino y cuatro por K/Ar en concentrados de sanidino. El análisis de los datos de paleomagnetismo y geocronológicos sugiere que la Ignimbrita Panalillo Superior está formada por al menos dos unidades de flujo con direcciones paleomagnéticas y edades isotópicas diferentes; la primera es de 28 Ma y está expuesta en los alrededores de la ciudad de San Luis Potosí (SLP) y la segunda es de aproximadamente 26.5 Ma y se presenta en el área La Pendencia. La dirección media del campo volcánico sugiere que el área de muestreo pudo haber rotado $7.9^{\circ} \pm 9.6^{\circ}$ en sentido anti-horario con respecto al cratón de Norte América desde el Oligoceno. Sin embargo, los valores obtenidos no son estadísticamente significativos y se pueden interpretar de manera alternativa como resultado del fallamiento complejo que afectó a la región desde el Paleógeno.
\end{abstract}

Palabras clave: Paleomagnetismo, Ignimbrita Panalillo Superior, Campo Volcánico de San Luis Potosí, volcanismo, Oligoceno, Mesa Central.

\section{Abstract}

The Oligocene Upper Panalillo Ignimbrite is widely distributed in the San Luis Potosi Volcanic Field, in the southeastern portion of the Mesa Central province of Mexico. It crops out sporadically over a 15,000 $\mathrm{km}^{2}$ area. The best exposures of the ignimbrite were sampled for paleomagnetic and geochronological studies, with sites grouped in five zones according to their geographic distribution and structural setting. The five zones are: northwest or La Pendencia (1); north or Valle Umbroso (2); center-north or Mexquitic 
(3); east or Panalillo (4); and, south or Bledos Graben (5). We determined virtual paleomagnetic poles (VGPs) and mean directions for each sampling site and for each one of the five zones. VGPs for the Upper Panalillo Ignimbrite were combined with published paleomagnetic data for the San Luis Potosi volcanic field in order to determine an Oligocene paleomagnetic pole located at $72.1^{\circ} \mathrm{N}$ $165.5^{\circ} \mathrm{E}\left(N=17, K=228.2\right.$, A95 $\left.=6.8^{\circ}\right)$, which was in turn compared with the North America reference pole. We determined rotation $(R)$ and flattening $(F)$ parameters for the region. The study was supplemented by seven radiometric ages for the ignimbrite, three are single crystal total fusion LASER ${ }^{40} \mathrm{Ar}{ }^{\beta 9} \mathrm{Ar}$ ages and four are $\mathrm{K} / \mathrm{Ar}$ for saninide separates. The combination of paleomagnetic data and isotopic age determinations suggests that the Upper Panalillo Ignimbrite is composed of at least two flow units with different paleomagnetic and radiometric ages. One unit is approximately $26.5 \mathrm{Ma}$ and it is mostly present in La Pendencia area; the other is ca. $28 \mathrm{Ma}$, and crops out around the city of San Luis Potosí. The overall mean for individual units of the volcanic field suggests that the region has experienced a counter-clockwise rotation of $7.9^{\circ} \pm 9.6^{\circ}$ with respect to the North America craton since the Oligocene. However, the estimate of rotation is not statistically significant, and it can be interpreted as an apparent tectonic rotation consequence of complex faulting that affected the region during Paleogene time.

Keywords: Paleomagnetism, Ignimbrita Panalillo Superior, San Luis Potosí Volcanic Field (CVSLP), volcanism, Oligocene, Mesa Central.

\section{Introducción}

La Ignimbrita Panalillo es una unidad litoestratigráfica formal (Labarthe-Hernández et al., 1982) del Oligoceno que aflora en el Campo Volcánico de San Luis Potosí (CVSLP), en la parte sudoriental de la Mesa Central. Esta unidad ha recibido atención reciente porque se ha sugerido que su origen está asociado a erupciones piroclásticas fisurales, a partir de diques piroclásticos emplazados en fallas normales en la Riolita San Miguelito y la Ignimbrita Cantera (Tristán-González et al., 2008; Torres-Hernández et al., 2006; Torres-Hernández, 2009).

El CVSLP está formado por una sucesión de lavas y flujos piroclásticos félsicos $\mathrm{y}$, en menor proporción, por andesitas y basaltos con edades isotópicas del Eoceno Medio al Mioceno Tardío. El emplazamiento de la ignimbrita Panalillo Superior sucedió durante una etapa tardía de volcanismo orogénico que tuvo un carácter bimodal (Tristán-González et al., 2009). El magmatismo en el CVSLP estuvo asociado en tiempo y espacio con tectónica extensional (Aranda-Gómez et al., 2007), que produjo fallas con rumbos que varían en rumbo de NW a $\mathrm{NE}$, siendo la etapa más joven la que formó fallas $\sim \mathrm{N}-\mathrm{S}$. Relaciones de corte y superposición entre una sucesión de ignimbritas y domos félsicos, al menos tres depósitos de gravas continentales de relleno de graben y varios arreglos de fallas normales formadas durante distintos pulsos de deformación demuestran la asociación espacio-temporal entre los eventos magmáticos y extensionales en la región (Aranda-Gómez et al., 2007).

Distintos autores han reportado direcciones paleomagnéticas discordantes para regiones del centro y norte de México, que generalmente se han interpretado en términos de rotaciones tectónicas de escala local con respecto a ejes verticales o en términos de fallas regionales de rumbo (e.g., Urrutia-Fucugauchi, 1981; Bobier y Robin, 1982; Goguitchaichvili et al., 2001; Andreani, 2008). La tendencia principal de los datos paleomagnéticos es mostrar rotaciones en sentido antihorario, que a su vez se han interpretado como producto de fallamiento lateral izquierdo. Nuestros resultados para el CVSLP también sugieren una rotación pequeña en sentido antihorario.

Uno de los problemas para interpretar rotaciones definidas por datos paleomagnéticos es establecer si el muestreo es suficiente para promediar la paleo-variación secular. Otro es entender el contexto estructural para explicar las rotaciones, ya que a la fecha no se ha encontrado en la parte meridional de la Mesa Central evidencia contundente de fallas con corrimientos laterales posteriores al CVSLP. Otros factores adicionales de incertidumbre son que la estratigrafía del CVSLP solo se conoce a escala regional y que los fechamientos radiométricos disponibles son relativamente escasos con relación al tamaño y complejidad estratigráfica y estructural del área. Los resultados paleomagnéticos pueden ser útiles para resolver esa estratigrafía en términos de sus implicaciones magnetoestratigráficas, ya que la correlación con la escala global de polaridad magnética permite reducir la incertidumbre en las edades isotópicas (e.g. ArandaGómez et al., 2007).

\section{Marco Geológico}

La Mesa Central se caracteriza por una cubierta de rocas volcánicas, principalmente félsicas, con espesor variable hasta de $1000 \mathrm{~m}$, que descansa sobre sedimentos mesozoicos deformados. El basamento prevolcánico es una sucesión de rocas sedimentarias marinas del Cretácico que afloran en pliegues regionales con rumbos N-S a NW-SE. El área ha sido cartografiada con relativo detalle (Labarthe-Hernández et al., 1982; Tristán-González, 2008; Tristán-González et al., 2009). Localmente, en la base de la sucesión volcánica cenozoica hay andesitas del Eoceno o rocas siliciclásticas continentales del Paleoceno-Eoceno. El mayor volumen del magmatismo félsico se emplazó en el lapso entre 32 y 26 Ma. Los productos volcánicos son calcialcalinos y están asociados a convergencia en el 
margen Pacífico (Orozco et al., 2002) y en muchos sitios muestran estructuras asociadas al evento extensional de Cuencas y Sierras. De manera similar a lo que sucede en la Sierra Madre Occidental, en la Mesa Central se puede reconocer que la transición de magmatismo asociado a un margen convergente a aquel de un ambiente extensional de intraplaca sucedió en el Mioceno Temprano entre los 24 y $20 \mathrm{Ma}$ (Aguirre-Díaz y McDowell, 1993).

El volcanismo del CVSLP produjo complejos grandes de domos félsicos y derrames de lava asociados, calderas y derrames piroclásticos extensos. Durante las últimas etapas de la actividad volcánica orogénica se emplazaron derrames piroclásticos de grado medio a alto que localmente muestran evidencia de reomorfismo. Un ejemplo de estas ignimbritas en parte reomórficas es la Ignimbrita Panalillo Superior. Aranda-Gómez et al. (2007) reconocieron en la región de Pinos (Figura 1) un pulso de deformación extensional anterior al evento magmático más voluminoso $(>32 \mathrm{Ma})$ y un patrón complejo de fallas contemporáneas y posteriores al magmatismo orogénico. Las fallas normales cenozoicas con orientaciones N-S, NW y NE son las principales responsables de la fisiografía actual del área.

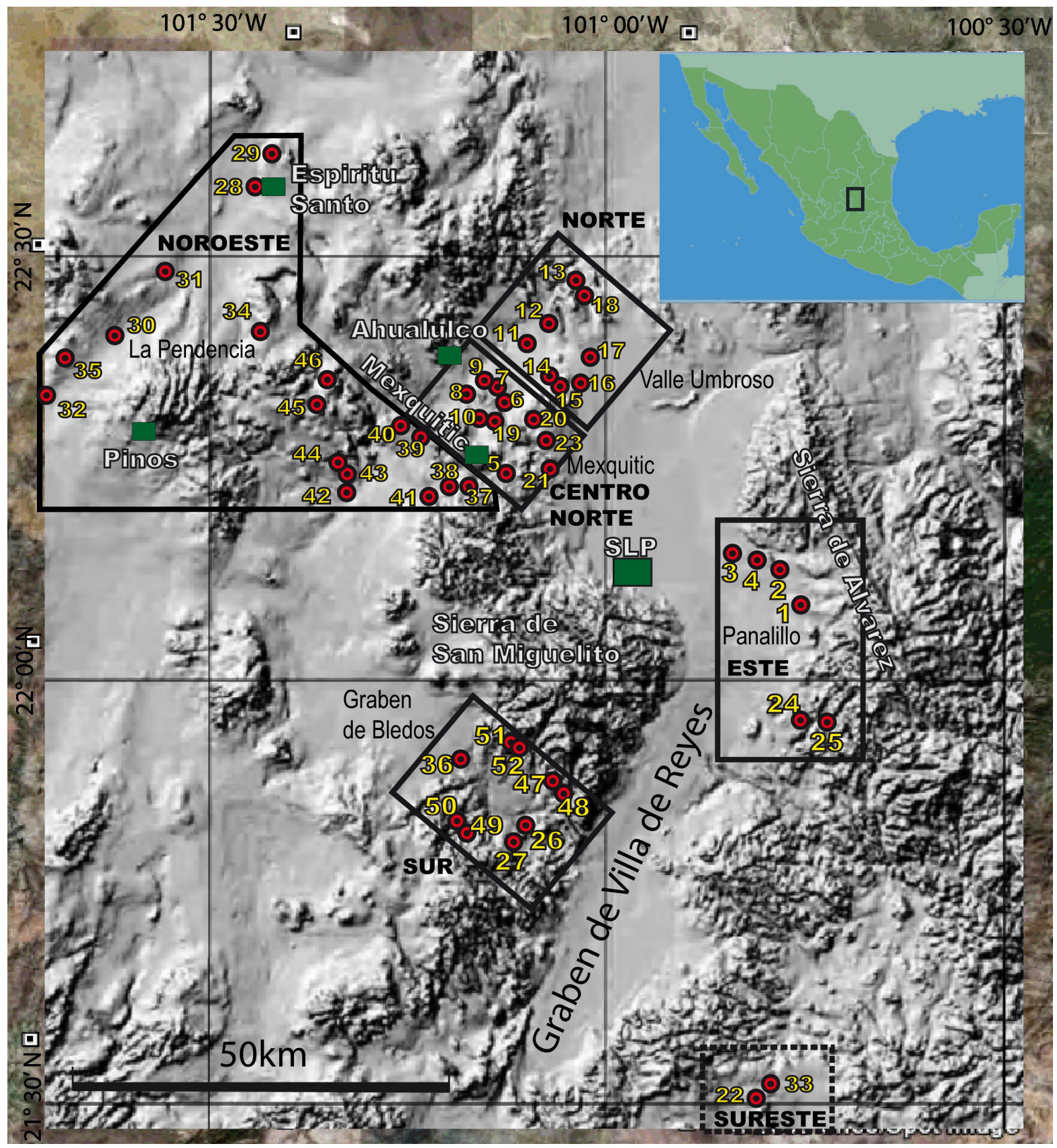

Figura 1.- Modelo digital de elevación que cubre parcialmente al Campo Volcánico de San Luis Potosí. Se muestran las cinco zonas donde se efectuó el muestreo paleomagnético, así como la ubicación de los sitios; SLP = Ciudad de San Luis Potosí. 
La Ignimbrita Panalillo, originalmente descrita por Labarthe-Hernández y Tristán-González (1978) en la cartografía de la Hoja San Luis Potosí, fue definida como una unidad litoestratigráfica formal por Labarthe-Hernández et al. (1982). Su localidad tipo está al poniente del poblado del Panalillo, al oriente de la ciudad de San Luis Potosí (SLP). La unidad aflora de manera esporádica adentro de una zona amplia del CVSLP (Figura 1). Esta formación se encuentra constituida por dos miembros. El miembro inferior está formado por rocas piroclástica que rellenaron zonas topográficamente bajas como el Graben de Villa de Reyes y el miembro superior que se presenta en vestigios erosionales coronando mesetas inclinadas (Figura 2). Existen algunas áreas donde los afloramientos del miembro superior son extensos, como en el Graben de Bledos, en el margen occidental del Graben de Villa de Reyes, en la región de Mexquitic, al este del poblado de Ahualulco, al oeste del poblado de Cerro Prieto, e incluso en los alrededores de Ojuelos, Jalisco (Figura 1).

El miembro inferior (Ignimbrita Panalillo Inferior) está formado por una toba de caída color crema a ligeramente rojiza (Torres-Hernández, 2009), bien estratificada, en capas de 5 a $30 \mathrm{~cm}$ de espesor, que varían de ceniza fina a gruesa y por depósitos epiclástico-volcánicos, en lugares conglomeráticos, con clastos líticos de $2-10$ $\mathrm{cm}$. Esporádicamente en la base del miembro inferior se encuentran también depósitos piroclásticos de oleada o de flujo. El miembro superior (Ignimbrita Panalillo Superior) es una ignimbrita densamente piroconsolidada y parcial a totalmente desvitrificada color café rojizo, café claro o rosa claro. Al microscopio tiene textura merocristalina, inequigranular-porfídica, con 5 a $10 \%$ de fenocristales de 1-2 mm de largo de cuarzo y sanidino en una mesostasis usualmente desvitrificada, compuesta por esquirlas de vidrio y fragmentos de pómez colapsada que definen una foliación eutaxítica. Comúnmente esta roca contiene algunos fragmentos líticos accidentales. En varias localidades tiene un vitrófido de 1-2 $\mathrm{m}$ de espesor en su base y en otros su contacto con el miembro inferior es un horizonte piroclástico sin piroconsolidar a parcialmente piroconsolidado (Valle Umbroso, Mexquitic). En el arroyo El Juachín, al NW del poblado de Pozuelos, sobre la carretera San LuisGuadalajara, la base del miembro superior cubre un basalto

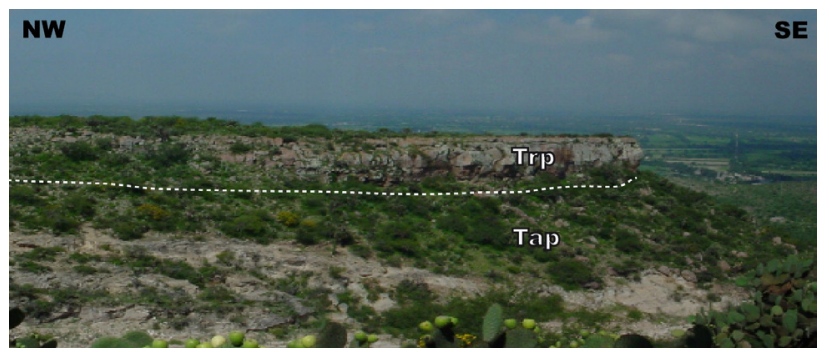

Figura 2. Afloramiento de la Ignimbrita Panalillo superior en las cercanías del poblado Espíritu Santo (Figura 1). El espesor de la ignimbrita es aproximadamente $20 \mathrm{~m}$ y corona la parte más alta del cerro. que descansa sobre la Riolita San Miguelito (TorresHernández et al., 2006).

La cima del miembro superior es una ignimbrita color gris rosáceo, café o gris rojizo, con textura inequigranularporfídica, con 10-15\% de fenocristales de $1-4 \mathrm{~mm}$ de cuarzo, sanidino y algunas plagioclasas. La matriz está casi totalmente desvitrificada y es un agregado microcristalino de composición felsítica en que comúnmente se distingue una foliación eutaxítica. En muchos sitios presenta numerosas esferulitas y litofisas de $2-12 \mathrm{~mm}$ de diámetro, generalmente rellenas de cuarzo, tridimita, cristobalita y/o calcedonia. En el campo, el miembro superior tiene una estructura columnar característica. Normalmente se encuentra afectada por fallas normales que bascularon estas mesetas al NE. El espesor total del miembro superior es $20 \mathrm{~m}$.

De acuerdo con Labarthe-Hernández (2007, comunicación personal) los dos miembros se formaron en eventos volcánicos independientes y pudieron haberse cartografiado como formaciones diferentes. Además de las diferencias litológicas entre los miembros, se ha sugerido la existencia de fuentes distintas para los miembros inferior y superior (Tristán-González, 2008; Torres-Hernández et al., 2006).

La edad isotópica aceptada para el miembro superior, determinada por K/Ar en roca completa en el borde oriental del valle de SLP, es de $26.8 \pm 1.3 \mathrm{Ma}$ (LabartheHernández et al., 1982). Por otra parte, McDowell (citado en SGM Carta San Luis Potosí, 2003) obtuvo una edad K/ Ar (sanidino) de $27.6 \pm 0.6$ Ma para el miembro superior de un banco de material localizado en el km 68.2 de la carretera San Felipe-Ojuelos. Dentro del error analítico las edades de Labarthe-Hernández et al. (1982) y McDowell son indistinguibles.

Se ha propuesto que el emplazamiento del miembro inferior fue a partir de fisuras y fallas normales que sirvieron como conductos para el ascenso del magma durante un pulso de tectónica extensional (Aguirre-Díaz y LabartheHernández, 2003; Torres-Hernández et al., 2006). El mecanismo de emplazamiento de la Ignimbrita Panalillo escapa los objetivos de este trabajo, pero la presencia de diques pircolásticos documentada por los autores citados apoya a esta interpretación.

\section{Metodología}

\subsection{Muestreo paleomagnético}

El muestreo paleomagnético de la Ignimbrita Panalillo Superior (IPS) se realizó en afloramientos sin intemperismo, ubicados cerca de la base de la unidad, en donde se supuso estaría protegida de descargas eléctricas - aunque esto no siempre fue cierto. Para el muestreo se utilizó una perforadora de gasolina enfriada con agua, obteniendo núcleos de $2.5 \mathrm{~cm}$ de diámetro con profundidades variables de 2.5 a $7.5 \mathrm{~cm}$; estos núcleos fueron orientados in situ 
con una brújula Brunton y cuando fue posible con brújula solar. En cada sitio se midió el rumbo y buzamiento que se emplearon para hacer la corrección estructural al momento de procesar los datos. Por cada sitio paleomagnético se tomaron de 6 a 11 muestras, conforme lo permitieron las características del terreno.

El muestreo paleomagnético se realizó en 52 sitios y generó un total de 432 núcleos. La ubicación de cada sitio fue determinada con un GPS con una precisión de $\pm 4 \mathrm{~m}$ (Tabla 1). Los sitios se agruparon en cinco zonas definidas con base a la distribución geográfica adentro del CVSLP, la actitud estructural de la ignimbrita y la continuidad de los afloramientos. La zona noroeste o La Pendencia (Figura 1) es el área más extensa (17 sitios). En esta zona la ignimbrita varía de horizontal a subhorizontal, con inclinaciones medidas inferiores a $5^{\circ}$. La zona norte o Valle Umbroso (Figura 1) incluye una serie de afloramientos en mesas basculadas al $\mathrm{NE}$ con ángulos de $10 \mathrm{a} 25^{\circ}$ y limitadas por fallas normales con rumbos NW-SE (Figura 3). En la zona centro-norte, que se encuentra entre Ahualulco y Mexquitic, también hay afloramientos basculados pero con una inclinación más variable; los ángulos de buzamiento varían entre 10 y $40^{\circ}$ al NE y las fallas normales que afectan la ignimbrita tienen rumbos NW-SE. En la zona este, o Panalillo, hay afloramientos levemente basculados $\left(<15^{\circ}\right)$, pero sin una orientación preferencial. Los afloramientos en la zona este son escasos y relativamente pequeños y vestigios de la ignimbrita coronan cerros aislados. En la zona Este se pueden diferenciar dos subzonas: Panalillo y La Escondida. La zona sur corresponde al Graben de Bledos, donde los afloramientos son subhorizontales $\left(<10^{\circ}\right)$ y se encuentran principalmente en los márgenes del graben. Originalmente se consideró una zona sureste, formada solamente por dos sitios cerca de El Naranjero. Sin embargo, no se obtuvieron resultados útiles en esta zona.

\subsection{Trabajo de laboratorio}

La mayoría de las mediciones se realizaron en el Laboratorio de Paleomagnetismo del Centro de Geociencias de la Universidad Nacional Autónoma de México. En el laboratorio se obtuvieron dos o tres especímenes de 2.1 $\mathrm{cm}$ por núcleo. Se seleccionó un espécimen de cada núcleo para ser desmagnetizado y otro para medir la anisotropía de la susceptibilidad.

Para cada muestra se realizó la corrección solar sobre el azimut tomado en campo, sin haber encontrado diferencias significativas entre ambas orientaciones. Después se procedió a medir la magnetización remanente natural (MRN) y la susceptibilidad magnética $(\chi)$ de cada espécimen. Para medir la susceptibilidad se utilizó un susceptibilímetro modelo KLY-3, pero esos resultados se reportarán en otra publicación. Las mediciones de remanencia se realizaron con un magnetómetro de giro JR-5, pero para algunos especímenes se utilizó un magnetómetro criogénico modelo 2G Enterprises en la Universidad de Hawaii en Manoa.
En al menos un espécimen por sitio se hizo desmagnetización piloto de al menos 13 pasos, ya sea por campos alternos (CA) o térmica (DT). Se identificaron varios sitios afectados por tormentas eléctricas que generaron una magnetización remanente isotermal, la cual fue posible borrar con CA en campos bajos $(<20 \mathrm{mT})$, por lo que a algunas muestras que fueron desmagnetizadas por el proceso térmico primero se les aplicó desmagnetización por CA hasta los $20 \mathrm{mT}$ y después se hizo desmagnetización térmica hasta $630^{\circ} \mathrm{C}$. Los demás especímenes se desmagnetizaron por CA.

Una vez hecha la desmagnetización se realizó un análisis visual de diagramas ortogonales (Zijderveld, 1967) para identificar las componentes de la magnetización y determinar la dirección característica, utilizándose la técnica de análisis de componentes principales. Finalmente, se calculó la dirección media de la IPS, utilizando las estadísticas de Fisher (1953).

Se realizaron diferentes análisis para identificar los minerales portadores de la magnetización. La adquisición de magnetización remanente isotermal (MRI) se midió con inducciones máximas de $3 \mathrm{~T}$ con un magnetómetro de pulsos. Se realizó mediciones de la susceptibilidad $(\chi)$ contra temperatura. Estas mediciones se llevaron a cabo en el laboratorio de paleomagnetismo del Instituto de Geofísica de la UNAM usando un susceptibilímetro Bartington CS2, utilizando aproximadamente $1 \mathrm{~g}$ de muestra. Curvas de histéresis permitieron generar una gráfica de Day (Day et al., 1977) donde se determinó el dominio preferencial de las partículas magnéticas. Estas mediciones se realizaron en los laboratorios de la Universidad de Hawaii en Manoa, EUA, y en el GeoForschungsZentrum en Potsdam, Alemania. En ambos casos se utilizó un VSM Micro Mag de Princeton Instruments.

La textura de los óxidos de Fe y Ti se examinó en un microscopio mineragráfico en un total de 18 secciones pulidas que incluyen muestras de todas las zonas de estudio. Se seleccionaron nueve de ellas para analizarlas en un microscopio electrónico de barrido JEOL JSM-6060 LV.

\section{Resultados paleomagnéticos}

\subsection{Zona noroeste (La Pendencia)}

En La Pendencia (unos $60 \mathrm{~km}$ al NW de la ciudad de SLP, Figura 1) la ignimbrita corona mesetas subhorizontales y aparentemente se emplazó siguiendo la paleotopografía, ya que en ciertos lugares - como en el cañón del Durazno - sigue el cauce de un paleovalle. La desmagnetización por CA indica que hay una componente de alta intensidad pero baja fuerza coercitiva, que puede ser removida con una inducción de $20 \mathrm{mT}$. Posteriormente, una trayectoria lineal hacia el origen define una magnetización de inclinación intermedia negativa dirigida al sureste (Figura 4a). Algunos de los especímenes tratados a $100 \mathrm{mT}$ no alcanzaron a definir 
Tabla 1. Datos paleomagnéticos y de ubicación para sitios en la Ignimbrita.

\begin{tabular}{|c|c|c|c|c|c|c|c|c|c|c|c|c|c|}
\hline \multirow[t]{2}{*}{ Zona / Sitio } & \multirow[t]{2}{*}{$n / N$} & \multicolumn{3}{|c|}{ "in situ" } & \multicolumn{5}{|c|}{ "Corrección estructural" } & \multirow[b]{2}{*}{ pol. } & \multicolumn{2}{|c|}{ Coordenadas Geográficas } & \multirow{2}{*}{ Características de la roca } \\
\hline & & D & $\mathbf{I}$ & $\mathbf{k}$ & $\alpha 95$ & $D$ & $I$ & $k$ & $\alpha 95$ & & $\mathrm{~N}$ & W & \\
\hline \multicolumn{14}{|c|}{ NOROESTE / LA PENDENCIA } \\
\hline P28 & - & - & - & - & - & - & - & - & - & - & $22^{\circ} 35^{\prime} 36.6^{\prime \prime}$ & $101^{\circ} 26^{\prime} 27.5^{\prime \prime}$ & Compacta sin litofisas \\
\hline P29 & $7 / 9$ & 160.8 & -37.5 & 59.3 & 7.9 & 161.2 & -42.5 & 59.3 & 7.9 & $\mathrm{R}$ & $22^{\circ} 37^{\prime} 54.2^{\prime \prime}$ & $101^{\circ} 25^{\prime} 10.4^{\prime \prime}$ & Compacta sin litofisas \\
\hline P30 & $7 / 9$ & 161.9 & -36.8 & 197.9 & 4.3 & 162.4 & -41.7 & 197.9 & 4.3 & $\mathrm{R}$ & $22^{\circ} 25^{\prime} 18.9^{\prime \prime}$ & $101^{\circ} 35^{\prime} 08.6^{\prime \prime}$ & Prácticamente sin litofisas \\
\hline P31 & $7 / 10$ & 164.2 & -33.3 & 34.0 & 10.5 & 164.2 & -33.3 & 34.0 & 10.5 & $\mathrm{R}$ & $22^{\circ} 29^{\prime} 21.8^{\prime \prime}$ & $101^{\circ} 33^{\prime} 05.0^{\prime \prime}$ & Compacta sin litofisas \\
\hline P32 & $7 / 9$ & 150.1 & -43.0 & 18.8 & 14.3 & 150.1 & -48.0 & 18.8 & 14.3 & $\mathrm{R}$ & $22^{\circ} 20^{\prime} 30.6^{\prime}$ & $101^{\circ} 42^{\prime} 50.4^{\prime}$ & Con litofisas sin rellenar \\
\hline P34 & - & - & - & - & - & - & - & - & - & - & $22^{\circ} 24^{\prime} 54.4^{\prime \prime}$ & $101^{\circ} 25^{\prime} 36.3^{\prime \prime}$ & Compacta sin litofisas \\
\hline P35 & $7 / 11$ & 160.6 & -24.3 & 75.3 & 7.0 & 161.1 & -29.2 & 75.3 & 7.0 & $\mathrm{R}$ & $22^{\circ} 23^{\prime} 45.9^{\prime \prime}$ & $101^{\circ} 40^{\prime} 59.4^{\prime \prime}$ & Litofisas menores $1 \mathrm{~cm}$ \\
\hline P37 & $7 / 11$ & 156.4 & -20.8 & 34.0 & 10.5 & 156.4 & -20.8 & 34.0 & 10.5 & $\mathrm{R}$ & $22^{\circ} 14^{\prime} 23.8^{\prime \prime}$ & $101^{\circ} 09^{\prime} 32.5^{\prime \prime}$ & Compacta sin litofisa \\
\hline P38 & $6 / 11$ & 175.9 & -22.1 & 27.9 & 12.9 & 175.9 & -22.1 & 27.9 & 12.9 & $\mathrm{R}$ & $22^{\circ} 14^{\prime} 05.0^{\prime \prime}$ & $101^{\circ} 11^{\prime} 19.2^{\prime \prime}$ & Compacta sin litofisas \\
\hline P39 & $4 / 9$ & 157.9 & -42.7 & 83.7 & 10.1 & 157.9 & -42.7 & 83.7 & 10.1 & $\mathrm{R}$ & $22^{\circ} 17^{\prime} 20.0^{\prime \prime}$ & $101^{\circ} 13^{\prime} 44.4^{\prime \prime}$ & Compacta sin litofisas \\
\hline P40 & $5 / 10$ & 160.1 & -35.0 & 51.1 & 10.8 & 160.1 & -35.0 & 51.1 & 10.8 & $\mathrm{R}$ & $22^{\circ} 17^{\prime} 38.0^{\prime \prime}$ & $101^{\circ} 16^{\prime} 06.9^{\prime \prime}$ & Compacta sin litofisa \\
\hline P41 & $6 / 10$ & 133.9 & -74.5 & 25.6 & 13.5 & 133.9 & -74.5 & 25.6 & 13.5 & $\mathrm{R}$ & $22^{\circ} 13^{\prime} 19.3^{\prime \prime}$ & $101^{\circ} 12^{\prime} 42.8^{\prime \prime}$ & Compacta sin litofisas \\
\hline P42 & - & - & - & - & - & - & - & - & - & - & $22^{\circ} 13^{\prime} 46.5^{\prime \prime}$ & $101^{\circ} 18^{\prime} 33.8^{\prime \prime}$ & Muy alterada, argilizada \\
\hline P43 & - & - & - & - & - & - & - & - & - & - & $22^{\circ} 14^{\prime} 46.1^{\prime \prime}$ & $101^{\circ} 18^{\prime} 15.4^{\prime \prime}$ & Muy dura alterada silicificada \\
\hline P44 & - & - & - & - & - & - & - & - & - & - & $22^{\circ} 15^{\prime} 39.3^{\prime \prime}$ & $101^{\circ} 19^{\prime} 39.1^{\prime \prime}$ & Con litofisas, poco alterada \\
\hline P45 & $9 / 9$ & 150.2 & -45.2 & 37.6 & 8.5 & 150.2 & -45.2 & 37.6 & 8.5 & $\mathrm{R}$ & $22^{\circ} 19^{\prime} 21.7^{\prime \prime}$ & $101^{\circ} 21^{\prime} 11.7^{\prime \prime}$ & Alterada, con litofisas \\
\hline P46 & $6 / 10$ & 159.1 & -24.1 & 13.1 & 16.3 & 159.1 & -24.1 & 13.1 & 16.3 & $\mathrm{R}$ & $22^{\circ} 20^{\prime} 58.2^{\prime \prime}$ & $101^{\circ} 20^{\prime} 11.9^{\prime \prime}$ & Roca sana sin litofisas \\
\hline media & $10 / 17$ & 156.4 & -34.6 & 61.7 & 6.2 & 156.4 & -36.6 & 56.2 & 6.5 & $\mathbf{R}$ & & & \\
\hline \multicolumn{14}{|c|}{ NORTE / VALLE UMBROSO } \\
\hline P11 & $7 / 9$ & 130.5 & -32.0 & 18.0 & 14.6 & 135.2 & -30.3 & 18.0 & 14.6 & $\mathrm{R}$ & $22^{\circ} 25^{\prime} 37.1^{\prime \prime}$ & $101^{\circ} 03^{\prime} 44.2^{\prime \prime}$ & litofisas rellenas Qz \\
\hline P12 & $7 / 9$ & 161.8 & -27.8 & 189.1 & 4.4 & 166.0 & -23.0 & 189.1 & 4.4 & $\mathrm{R}$ & $22^{\circ} 24^{\prime} 23.8^{\prime \prime}$ & $101^{\circ} 02^{\prime} 20.5^{\prime \prime}$ & Compacta sin litofisas \\
\hline P13 & $7 / 10$ & 158.2 & -34.8 & 48.0 & 8.8 & 164.5 & -27.0 & 48.0 & 8.8 & $\mathrm{R}$ & $22^{\circ} 28^{\prime} 37.4^{\prime \prime}$ & $101^{\circ} 01^{\prime} 55.9^{\prime \prime}$ & Con litofisas rellenas $2-3 \mathrm{~cm}$ \\
\hline P14 & $7 / 8$ & 153.2 & -31.2 & 253.2 & 3.8 & 159.1 & -24.5 & 253.2 & 3.8 & $\mathrm{R}$ & $22^{\circ} 21^{\prime} 44.3^{\prime \prime}$ & $101^{\circ} 03^{\prime} 06.1^{\prime \prime}$ & Compacta sin litofisas \\
\hline P15 & $7 / 8$ & 152.3 & -30.7 & 31.6 & 10.9 & 158.1 & -24.1 & 31.6 & 10.9 & $\mathrm{R}$ & $22^{\circ} 21^{\prime} 27.2^{\prime \prime}$ & $101^{\circ} 02^{\prime} 37.8^{\prime \prime}$ & Compacta sin litofisas \\
\hline P16 & $7 / 10$ & 163.0 & -26.7 & 44.9 & 9.1 & 167.2 & -18.3 & 44.9 & 9.1 & $\mathrm{R}$ & $22^{\circ} 21^{\prime} 37.0^{\prime \prime}$ & $101^{\circ} 01^{\prime} 16.4^{\prime \prime}$ & A, B vesiculado, C-J sin ellas \\
\hline P17 & $7 / 9$ & 153.0 & -30.3 & 43.1 & 9.3 & 158.7 & -23.6 & 43.1 & 9.3 & $\mathrm{R}$ & $22^{\circ} 23^{\prime} 17.3^{\prime \prime}$ & $101^{\circ} 00^{\prime} 28.3^{\prime \prime}$ & Compacta sin litofisas \\
\hline P18 & $7 / 8$ & 161.3 & -27.6 & 32.2 & 10.8 & 165.8 & -19.5 & 32.2 & 10.8 & $\mathrm{R}$ & $22^{\circ} 27^{\prime} 45.7^{\prime \prime}$ & $101^{\circ} 01^{\prime} 13.1^{\prime \prime}$ & Con litofisas 3cm \\
\hline media & $7 / 8$ & 157.6 & -29.9 & 267.0 & 3.7 & 162.8 & -22.9 & 293.9 & 3.5 & $\mathbf{R}$ & & & \\
\hline CENTRO NO & RTE / M & AEXQUIר & TIC & & & & & & & & & & \\
\hline P5 & $7 / 10$ & 144.7 & -32.3 & 253.2 & 3.8 & 154.3 & -32.4 & 253.2 & 3.8 & $\mathrm{R}$ & $22^{\circ} 15^{\prime} 55.7^{\prime \prime}$ & $101^{\circ} 06^{\prime} 55.7^{\prime \prime}$ & Con litofisas $+.2 \mathrm{~cm}$ no rellena \\
\hline P6 & $5 / 6$ & 131.5 & -34.7 & 3.5 & 48.4 & 138.5 & -37.3 & 3.5 & 48.4 & $\mathrm{R}$ & $22^{\circ} 20^{\prime} 40.4^{\prime \prime}$ & $101^{\circ} 09^{\prime} 41.5^{\prime \prime}$ & Con litofisas +-1cm con Qz \\
\hline $\mathrm{P} 7 *$ & $8 / 8$ & 129.0 & -40.5 & 89.1 & 5.9 & 137.6 & -43.4 & 89.1 & 5.9 & $\mathrm{R}$ & $22^{\circ} 21^{\prime} 20.9^{\prime \prime}$ & $101^{\circ} 09^{\prime} 38.5^{\prime \prime}$ & Con litofisas $1 \mathrm{~cm}$ con Qz \\
\hline P8 & $5 / 6$ & 157.2 & -37.0 & 127.5 & 6.8 & 174.1 & -29.8 & 127.5 & 6.8 & $\mathrm{R}$ & $22^{\circ} 20^{\prime} 58.3^{\prime \prime}$ & $101^{\circ} 08^{\prime} 49.4^{\prime \prime}$ & Compacta - sin litofisas \\
\hline P9 & $5 / 6$ & 138.3 & -34.3 & 4.9 & 38.4 & 147.7 & -32.8 & 4.9 & 38.4 & $\mathrm{R}$ & $22^{\circ} 20^{\prime} 13.9^{\prime \prime}$ & $101^{\circ} 07^{\prime} 22.2^{\prime \prime}$ & Compacta sin litofisas \\
\hline P10 & $6 / 8$ & 141.0 & -32.2 & 74.7 & 7.8 & 148.1 & -27.8 & 74.7 & 7.8 & $\mathrm{R}$ & $22^{\circ} 19^{\prime} 02.7^{\prime \prime}$ & $101^{\circ} 07^{\prime} 26.1^{\prime \prime}$ & Compacta sin litofisas \\
\hline P19 & $7 / 9$ & 139.3 & -47.2 & 17.6 & 14.8 & 160.1 & -35.1 & 17.6 & 14.8 & $\mathrm{R}$ & $22^{\circ} 19^{\prime} 10.0^{\prime \prime}$ & $101^{\circ} 07^{\prime} 10.3^{\prime \prime}$ & Compacta sin litofisas \\
\hline P20 & $5 / 8$ & 142.1 & -22.7 & 94.7 & 7.9 & 153.5 & -23.7 & 94.7 & 7.9 & $\mathrm{R}$ & $22^{\circ} 20^{\prime} 59.3^{\prime \prime}$ & $101^{\circ} 07^{\prime} 56.8^{\prime \prime}$ & Compacta sin litofisas \\
\hline P21 & $6 / 9$ & 137.9 & -39.6 & 33.2 & 11.8 & 160.1 & -40.0 & 33.2 & 11.8 & $\mathrm{R}$ & $22^{\circ} 17^{\prime} 32.0^{\prime \prime}$ & $101^{\circ} 04^{\prime} 06.6^{\prime \prime}$ & Litofisas grandes $+10 \mathrm{~cm}$ \\
\hline P23 & $7 / 12$ & 153.3 & -30.5 & 44.9 & 9.1 & 167.3 & -25.7 & 44.9 & 9.1 & $\mathrm{R}$ & $22^{\circ} 18^{\prime} 47.4^{\prime \prime}$ & $101^{\circ} 04^{\prime} 48.8^{\prime \prime}$ & Compacta sin litofisas \\
\hline media & $7 / 10$ & 145.2 & -34.7 & 69.5 & 7.3 & 159.6 & -30.9 & 72.5 & 7.1 & $\mathbf{R}$ & & & \\
\hline ESTE / PAN & LILLO & & & & & & & & & & & & \\
\hline P1 & $8 / 10$ & 162.1 & -33.0 & 219.6 & 3.7 & 157.7 & -26.5 & 219.6 & 3.7 & $\mathrm{R}$ & $22^{\circ} 05^{\prime} 44.5^{\prime \prime}$ & $100^{\circ} 44^{\prime} 16.0^{\prime \prime}$ & Compacta-sin litofisas \\
\hline P2 & $8 / 10$ & 162.9 & -26.9 & 260.4 & 3.4 & 163.9 & -30.4 & 260.4 & 3.4 & $\mathrm{R}$ & $22^{\circ} 08^{\prime} 20.8^{\prime \prime}$ & $100^{\circ} 45^{\prime} 52.5^{\prime \prime}$ & Compacta-sin litofisas \\
\hline P3 & $9 / 9$ & 151.0 & -28.5 & 61.7 & 7.1 & 153.4 & -26.6 & 61.7 & 7.1 & $\mathrm{R}$ & $22^{\circ} 09^{\prime} 30.1^{\prime \prime}$ & $100^{\circ} 49^{\prime} 36.4^{\prime \prime}$ & Compacta sin litofisas \\
\hline P4 & $8 / 11$ & 159.6 & -29.1 & 104.3 & 6.6 & 165.3 & -31.3 & 104.3 & 6.6 & $\mathrm{R}$ & $22^{\circ} 09^{\prime} 30.1^{\prime \prime}$ & $100^{\circ} 47^{\prime} 36.9^{\prime \prime}$ & Compacta sin litofisas \\
\hline P24 & $7 / 9$ & 162.5 & 19.0 & 26.0 & 22.1 & 161.0 & 22.0 & 26.0 & 22.1 & $\mathrm{R}$ & $21^{\circ} 57^{\prime} 32.6^{\prime \prime}$ & $100 " 44^{\prime} 22.4^{\prime \prime}$ & Vesículas de $2 \mathrm{~cm}$ a $10-15 \mathrm{~cm}$ \\
\hline P25 & $4 / 11$ & 159.6 & -33.3 & 8.6 & 46.0 & 164.7 & -26.6 & 8.6 & 46.0 & $\mathrm{R}$ & $21^{\circ} 57^{\prime} 25.6^{\prime \prime}$ & $100^{\circ} 42^{\prime} 23.3^{\prime \prime}$ & Compacta sin litofisas \\
\hline media & $4 / 6$ & 158.9 & -29.5 & 223.6 & 6.2 & 160.0 & -28.8 & 219.6 & 6.2 & $\mathbf{R}$ & & & \\
\hline SUR / GRA & EN DE B & BLEDOS & & & & & & & & & & & \\
\hline P26 & $7 / 10$ & 146.8 & -28.2 & 48.0 & 8.8 & 149.2 & -26.2 & 48.0 & 8.8 & $\mathrm{R}$ & $21^{\circ} 49^{\prime} 58.3^{\prime \prime}$ & $101^{\circ} 05^{\prime} 33.4^{\prime \prime}$ & A-F vitrófido; G-K sana sin ves. \\
\hline P27 & $6 / 10$ & 122.2 & -1.8 & 4.3 & 36.6 & 122.4 & -2.0 & 4.3 & 36.6 & $\mathrm{R}$ & $21^{\circ} 49^{\prime} 03.6^{\prime \prime}$ & $101^{\circ} 06^{\prime} 18.2^{\prime \prime}$ & Sin litofisas-un poco alterada \\
\hline P36 & $7 / 8$ & 169.1 & -32.8 & 38.1 & 9.9 & 171.2 & -29.4 & 38.1 & 9.9 & $\mathrm{R}$ & $21^{\circ} 54^{\prime} 40.4^{\prime \prime}$ & $101^{\circ} 10^{\prime} 25.0^{\prime \prime}$ & Sin litofisas \\
\hline P47 & $7 / 9$ & 169.8 & -33.6 & 20.9 & 13.5 & 169.8 & -33.6 & 20.9 & 13.5 & $\mathrm{R}$ & $21^{\circ} 48^{\prime} 59.2^{\prime \prime}$ & $101^{\circ} 02^{\prime} 05.1^{\prime \prime}$ & Roca sana sin litofisas \\
\hline P48 & - & - & - & - & - & - & - & - & - & - & $21^{\circ} 48^{\prime} 53.0^{\prime \prime}$ & $101^{\circ} 01^{\prime} 51.6^{\prime \prime}$ & Roca sana sin litofisas \\
\hline P49 & $5 / 8$ & 339.6 & 36.2 & 110.8 & 7.3 & 339.6 & 36.2 & 110.8 & 7.3 & $\mathrm{~N}$ & $21^{\circ} 49^{\prime} 25.3^{\circ}$ & $101^{\circ} 09^{\prime} 36.5^{\prime \prime}$ & Roca muy argilizada \\
\hline P50 & $5 / 8$ & 344.0 & 56.6 & 143.9 & 6.4 & 344.0 & 56.6 & 143.9 & 6.4 & $\mathrm{~N}$ & $21^{\circ} 49^{\prime} 34.6 "$ & $101^{\circ} 09^{\prime} 40.5^{\prime \prime}$ & Roca sana sin litofisas \\
\hline P51 & $0 / 10$ & - & - & - & - & - & - & - & - & - & $21^{\circ} 53^{\prime} 23.7^{\prime \prime}$ & $101^{\circ} 07^{\prime} 55.3^{\prime \prime}$ & Roca alterada \\
\hline P52 & $0 / 10$ & - & - & - & - & - & - & - & - & - & $21^{\circ} 53^{\prime} 19.6^{\prime \prime}$ & $101^{\circ} 05^{\prime} 20.5^{\prime \prime}$ & Roca sana, sin litofisas \\
\hline media & $3 / 9$ & 161.8 & -32.0 & 49.0 & 17.8 & 163.3 & -30.1 & 50.7 & 17.5 & $\mathbf{R}$ & & & \\
\hline Combinado & 7 & 160.1 & -30.5 & 104.6 & 5.9 & 161.5 & -29.5 & 108.0 & 5.8 & & & & \\
\hline SURESTE & & & & & & & & & & & & & \\
\hline P22 & $0 / 12$ & - & - & - & - & - & - & - & - & ${ }^{\circ}$ & $21^{\circ} 30^{\prime} 54.6^{\prime \prime}$ & $100^{\circ} 47^{\prime} 39.5^{\prime \prime}$ & Muy vesiculada, alterada \\
\hline P33 & $0 / 7$ & - & - & - & - & - & - & - & - & 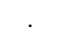 & $21^{\circ} 31^{\prime} 50.1^{\prime \prime}$ & $100^{\circ} 46^{\prime} 51.1^{\prime}$ & litofisas sin rellenar, alterada \\
\hline media & $0 / 2$ & & & & & & & & & & & & \\
\hline
\end{tabular}

Nota: Los sitios sombreados se eliminan del cálculo de la media por:

a) no definen dirección (p22,p25, P28, p33,p34, p42, p43, p44, p48, p51 y p52)

b) tener malas estadisticas, k muy baja y a95 muy alta, (p6 y p9)

c) ser outliers en su zona (p11,p24,p38 y p41)

d) pertenecen a otra unidad de roca (Ignimbrita cantera) (p49 y p50) 


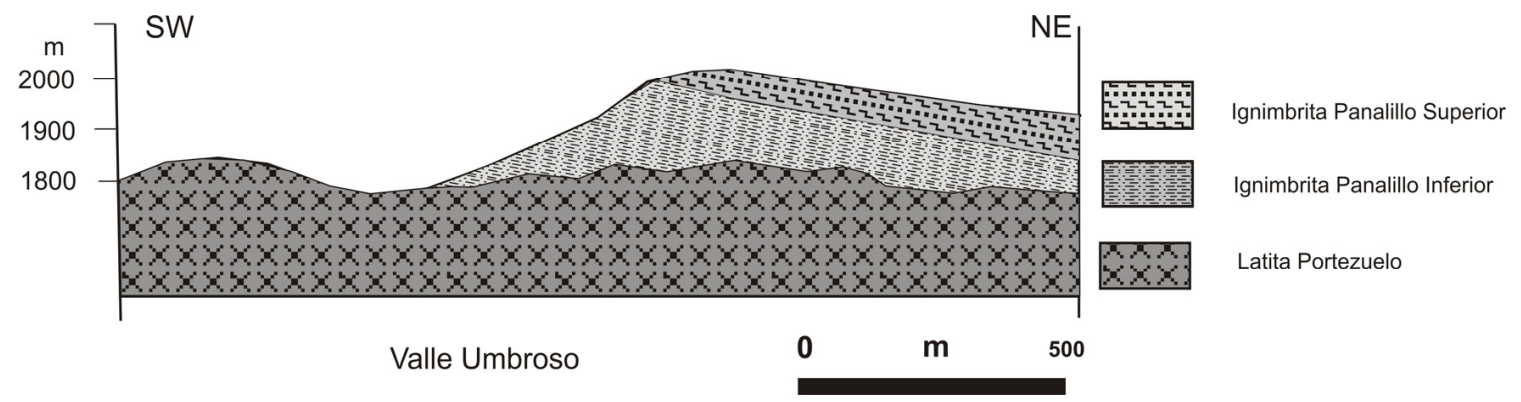

Figura 3. Sección esquemática idealizada de las relaciones de contacto entre las unidades volcánicas expuestas en la zona de Valle Umbroso. Se puede observar el basculamiento en los miembros superior e inferior de la Ignimbrita Panalillo, que descansa sobre la Latita Portezuelo.
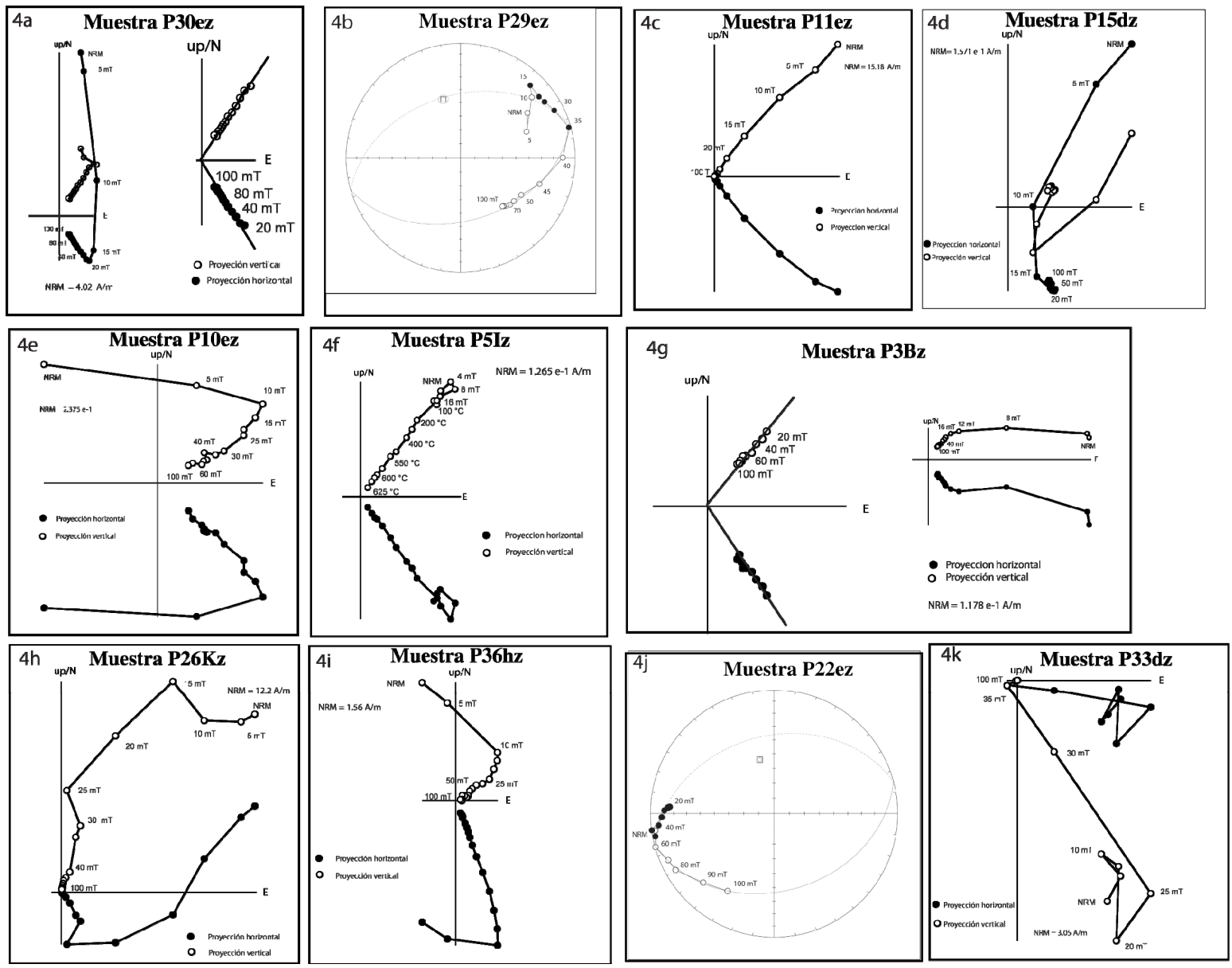

Figura 4. Diagramas ortogonales de desmagnetización de especímenes representativos de cada una de las zonas estudiadas. (a) La Pendencia, (c-d) Valle Umbroso, (e-f) Ahualulco-Mexquitic, (g) Panalillo, (h-i) Graben de Bledos, (k) zona sureste. Las figuras 4b y 4j muestran proyecciones estereográficas que ilustran la desmagnetización de muestras que definen círculos mayores para el área La Pendencia (b) y sureste (j).

una dirección característica; sin embargo, definen un plano en la proyección estereográfica (Figura 4b). En esos casos se determinaron las direcciones características combinando círculos mayores y direcciones definidas por segmentos lineales. Los valores de desviación angular máxima (DAM) variaron entre 1 y 6 , pero preponderantemente fueron menores a 3 (para ambos casos líneas y planos).
De los 17 sitios muestreados en esta zona, en cinco la calidad de los datos no fue suficiente para obtener la dirección característica (Tabla 1). Adicionalmente, el sitio P41 que tiene una inclinación alta $\left(-74.5^{\circ}\right)$ y se distingue estadísticamente del resto de los datos por lo que fue excluido. Las muestras de P28 y P34 fueron tomadas de la parte inferior de la ignimbrita, en donde no hay vesículas 
ni evidencias claras de alteración, por lo que las litofisas no parecen ser factor de inestabilidad en el registro magnético; más bien, esta inestabilidad en la magnetización de las muestras puede atribuirse a la influencia de magnetizaciones secundarias de carácter viscoso o isotermal, lo que causa una mayor dispersión en algunos sitios. El parámetro de precisión k varía entre 13.1 y 197.9.

La dirección característica media in situ $(\mathrm{N}=10)$ es de $\mathrm{D}=156.4^{\mathrm{o}} ; \mathrm{I}=-34.6^{\circ} ;\left(\mathrm{k}=61.7 ; \alpha 95=6.2^{\circ}\right)$ y si se aplica una corrección estructural, la dirección es estadísticamente indistinguible $\left(\mathrm{D}=156.4^{\circ} ; \mathrm{I}=-36.6^{\circ} ;(\mathrm{k}=56.2 ; \alpha 95=\right.$ $\left.6.5^{\circ}\right)$; Figura 5a, Tabla 1$)$; el parámetro de precisión en la estadística de Fisher disminuye ligeramente.
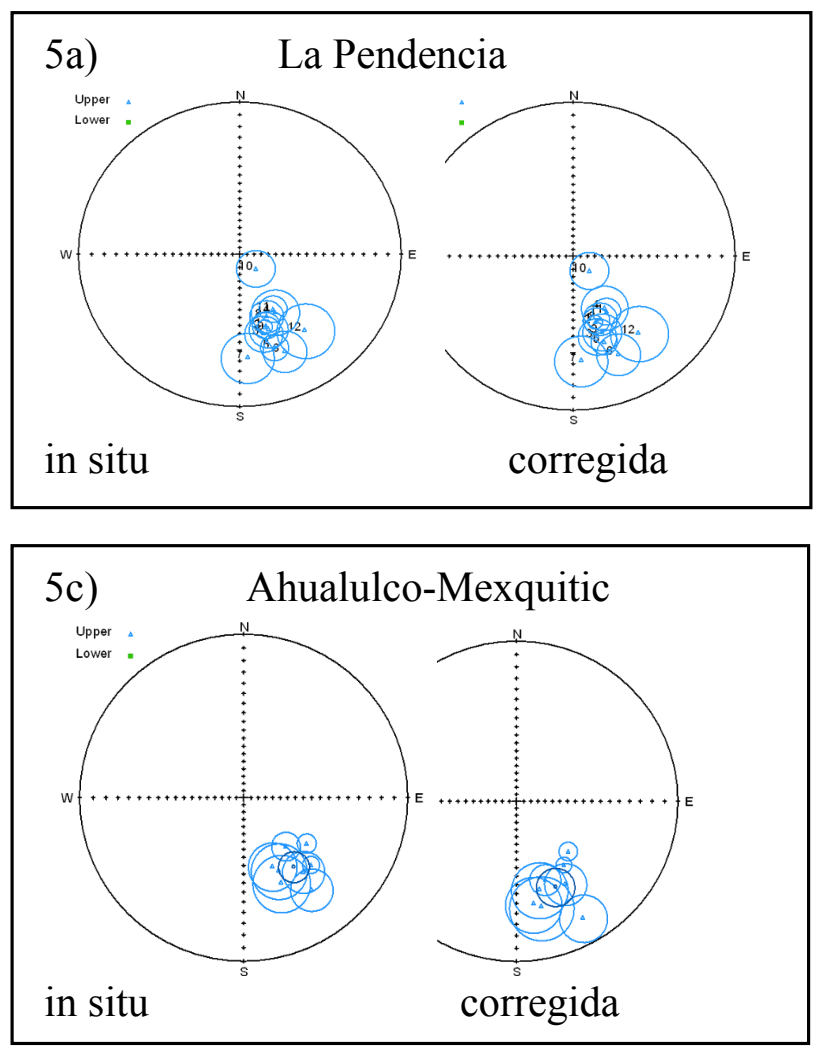

\subsection{Zona norte (Valle Umbroso)}

La zona de Valle Umbroso está al NE de la zona de Mexquitic-Ahualulco y al este de la zona La Pendencia (Figura 1); en esta zona la IPS corona mesetas alargadas con una orientación general NW-SE. Los resultados de la desmagnetización señalan comportamientos variables. Algunos sitios muestran una sola componente bien definida por un segmento lineal dirigido al origen, como en la muestra P11ez (Figura 4c), y otros especímenes muestran comportamiento multivectorial. En esos casos una componente es de dirección aleatoria y con coercitividad
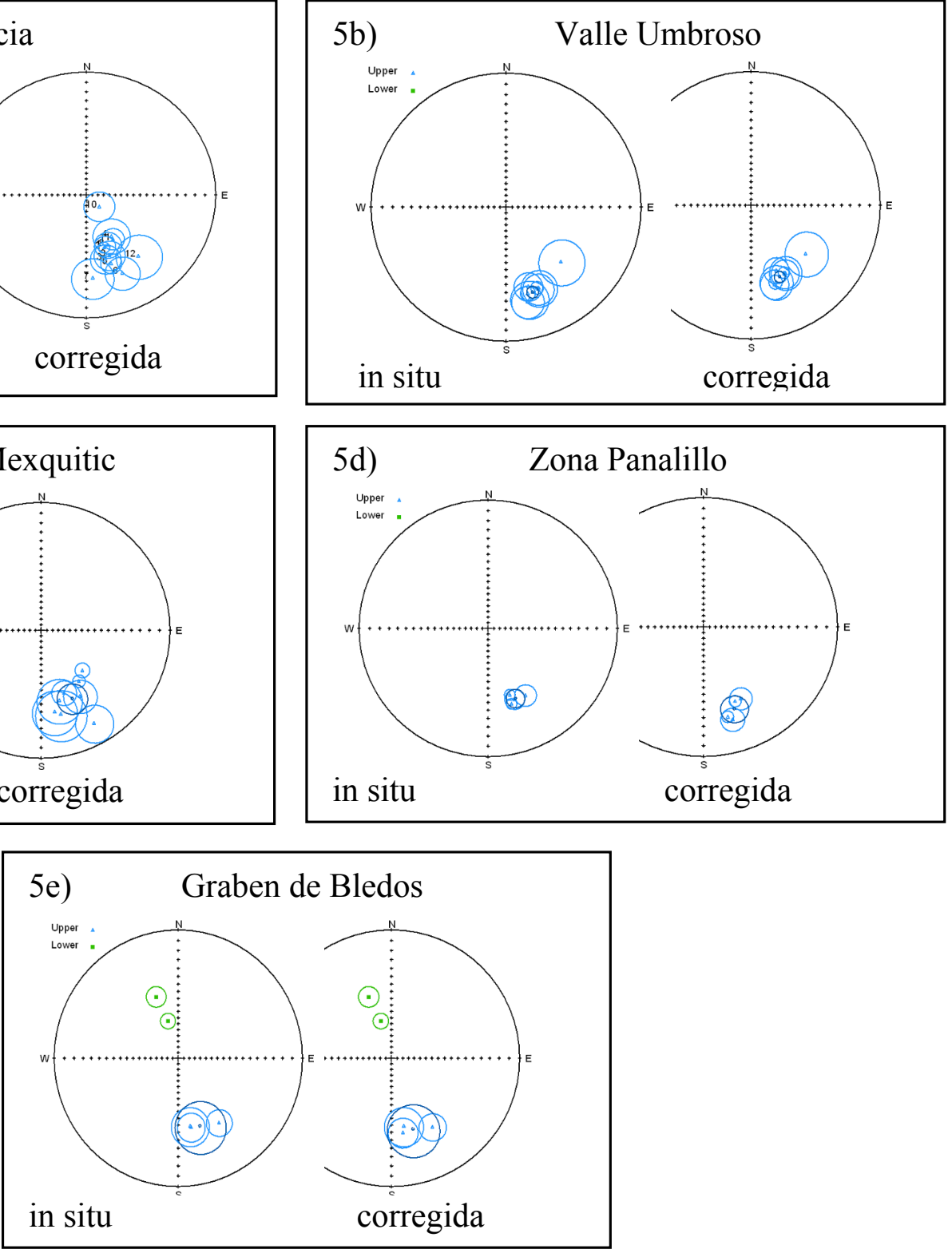

Figura 5.- Proyecciones estereográficas mostrando las medias de los sitios con su respectivo intervalo de confianza de cada una de las zonas estudiadas, in situ y corregidas estructuralmente. (a) La Pendencia, (b) Valle Umbroso, (c) Ahualulco-Mexquitic, (d) Panalillo, (e) Graben de Bledos. Para cada zona se muestra también la media con una estrella y el intervalo de confianza 
máxima de unas $10 \mathrm{mT}$, otra una componente de polaridad normal (dirigida al norte) se define de manera cruda entre los 10 y $20 \mathrm{mT}$ y una componente característica es de polaridad reversa. Ésta no alcanza a desmagnetizar completamente con $100 \mathrm{mT}$, para formar un punto estable final como en la muestra P15dz (Figura 4d). La magnetización característica (MC) de esta zona está bien definida, con una dispersión entre sitios más baja que en la zona de La Pendencia (mayor valor de $\mathrm{k}$ y menor valor de $\alpha 95$ ). Eliminando un sitio (P11) en que las estadísticas son pobres, la dirección media es $\mathrm{N}=7$ es: in situ $\mathrm{D}=157.6^{\circ} ; \mathrm{I}=-29.9^{\circ} ;\left(\mathrm{k}=267.09 ; \alpha 95=3.7^{\circ}\right)$ y corregidas estructuralmente $\mathrm{D}=162.8^{\circ} ; \mathrm{I}=-22.9^{\circ} ;(\mathrm{k}=$ 293.9; $\alpha 95=3.5^{\circ}$; Tabla 1, Figura $5 b$ ).

\subsection{Zona centro-norte (Mexquitic-Ahualulco)}

Esta zona está a $30 \mathrm{~km}$ al NW de la ciudad de SLP (Figura 1). Ahí la ignimbrita forma lomeríos alargados con rumbo NW-SE, siguiendo la tendencia de las fallas cenozoicas regionales. En esta zona hay 10 sitios de muestreo los cuales mostraron una $\mathrm{MC}$ de polaridad reversa con inclinaciones negativas, de intermedias a bajas. La intensidad de la MRN es alta, del orden de $10^{0}$ a $10^{-2} \mathrm{~A} / \mathrm{m}$, lo que es característico de rocas que han sufrido magnetizaciones secundarias del tipo MRI. Muchas de las muestras tienen al menos dos componentes. En algunos sitios la componente de baja coercitividad es de carácter isotermal (causada por rayos) como en la muestra P10ez (Figura 4e), aunque en ocasiones las componentes secundarias son pequeñas como en la muestra P5iz (Figura 4f) y están orientada hacia el norte con inclinación positiva.

La MC está dirigida al sureste y es inferida a partir de segmentos lineales en los diagramas de desmagnetización entre 25 y $100 \mathrm{mT}$, reteniendo aún $\sim 10 \%$ de la MRN a esa nivel de tratamiento. De igual manera, la $\mathrm{MC}$ se define por segmentos lineales entre 200 y $625{ }^{\circ} \mathrm{C}$, mostrando temperaturas de bloqueo distribuidas, pero casi un $80 \%$ de ella es removida al calentar a $600^{\circ} \mathrm{C}$. Con ambos métodos de desmagnetización se obtienen direcciones similares.

La dirección de la MC está bien definida en muestras individuales, con valores de DAM entre 1 y 5 . Las direcciones medias de cada sitio se muestran en la Tabla 1 y en la Figura $5 \mathrm{c}$. La dispersión entre sitios también es relativamente baja, pero un sitio (P7) se distingue del resto; el sitio P7 fue excluido del cálculo final porque además de tener una dirección distinta al resto, es un sitio donde la corrección estructural es incierta. Esta incertidumbre es también sugerida por un comportamiento anómalo de la anisotropía de la susceptibilidad magnética, donde la foliación magnética no es cercana a la actitud aparente. En siete de 10 sitios las estadísticas de Fisher permiten definir una dirección media, con los siguientes parámetros: in situ $\mathrm{D}=145.2^{\circ} ; \mathrm{I}=-34.7^{\circ} ;\left(\mathrm{k}=69.5 ; \alpha 95=7.3^{\circ}\right) ; \mathrm{y}$ realizando corrección estructural $\mathrm{D}=159.6^{\circ} ; \mathrm{I}=-30.9^{\circ} ;(\mathrm{k}=72.5$; $\alpha 95=7.1^{\circ}$ ). Los valores del parámetro de precisión $\mathrm{k}$ son estadísticamente aceptables y comparables a los de las otras zonas. Al momento de realizar la corrección estructural $\mathrm{k}$ no cambia de forma significativa, solo aumenta un poco, situación que podría explicarse por la poca variación en los echados.

\subsection{Zona este (Panalillo-La Escondida)}

Esta zona está al oriente de la ciudad de SLP e incluye a la localidad tipo de la IPS. En la subzona Panalillo se muestrearon cuatro sitios que corresponden a diferentes mesetas (Figura 1). La desmagnetización de CA identifica dos componentes. Una es de orientación errática y baja coercitividad $(<20 \mathrm{mT})$; esto se puede observar en la muestra P3bz (Figura 4g). Esta componente es probablemente una MRI debida a tormentas eléctricas. Una vez removida esta magnetización, es posible determinar una MC de polaridad reversa con una inclinación negativa con valores moderados. La MC se define por intervalos lineales entre 20 y 100 $\mathrm{mT}$, pero aproximadamente $40 \%$ de la MC resiste campos alternos hasta de $100 \mathrm{mT}$. Los valores de DAM en los cuatro sitios de esta localidad varían entre $1.5^{\circ}$ y $5^{\circ}$.

En la subzona de La Escondida hay solo dos sitios (P24 y P25) ya que los afloramientos son escasos, se encuentran muy intemperizados o son de acceso difícil. El comportamiento de las muestras de estos dos sitios es errático, ya que se desmagnetizan rápidamente (en $20 \mathrm{mT}$ ) y presentan comportamientos erráticos cerca del origen. En el sitio P24 se encontró una dirección utilizando solamente círculos mayores. Sin embargo, la media no se considera confiable: 1) por no tener al menos una muestra definida por segmentos lineales, 2) por tener rangos de coercitividad bajos para definir a los círculos mayores y 3 ) por tener un $\alpha 95$ elevado.

Las estadísticas de Fisher de los cuatro sitios de la subzona Panalillo definen una dirección in situ de $\mathrm{D}=$ $158.9^{\circ} ; \mathrm{I}=-29.5^{\circ} ;\left(\mathrm{n}=4 ; \mathrm{k}=223.6 ; \alpha 95=6.2^{\circ}\right)$. Al hacer la corrección estructural la dirección cambia ligeramente: $\mathrm{D}=160^{\circ} ; \mathrm{I}=-28.8^{\circ}\left(\mathrm{k}=219.6\right.$ y $\left.\alpha 95=6.2^{\circ}\right)$. Se puede apreciar que el parámetro $\mathrm{k}$ no cambia significativamente (Tabla 1, Figura 5d).

\subsection{Zona sur (Graben de Bledos)}

El Graben de Bledos está al sur de la ciudad de SLP (Figura 1). La estructura está formada por fallas NW-SE y la ignimbrita aflora a lo largo de sus márgenes, aunque también existen afloramientos adentro del graben, en donde la unidad corona la cima de cerros aislados. En este lugar se muestrearon nueve sitios. Sin embargo, dos de ellos (P49 y P50) corresponden a la Ignimbrita Cantera que subyace a la IPS. Otros tres sitios no permitieron definir una dirección media (P48, P51 y P52); su registro paleomagnético es errático y se atribuye a alteración o intemperismo.

En el sitio P26 se perforó en vitrófido y en roca desvitrificada. El comportamiento de remanencia magnética fue similar en ambas litologías. En este sitio se encontró una 
dirección secundaria que fue posible eliminar a los $30 \mathrm{mT}$, y posteriormente se definió una $\mathrm{MC}$ inversa de inclinación alta y negativa. En el sitio P36 también se ven dos componentes, una parece ser viscosa porque está dirigida al norte y se remueve a los 10-15 mT, definiéndose una dirección inversa de inclinación media negativa (Figuras $4 \mathrm{~h}$ y $4 \mathrm{i}$ ). En este caso inducciones de $100 \mathrm{mT}$ son suficientes para desmagnetizar casi por completo las muestras de estos sitios; la coercitividad media de la $\mathrm{MC}$ es alta (mayor a $50 \mathrm{mT}$ ). En cuatro sitios fue posible definir una dirección media; sin embargo, uno fue excluido debido a que las estadísticas son de menor calidad. La media para $\mathrm{N}=3$, in situ, es $\mathrm{D}$ $=161.7^{\circ}, \mathrm{I}=-32.0^{\circ}\left(\mathrm{k}=49.0\right.$ y $\left.\alpha 95=17.8^{\circ}\right)$; aplicando la corrección estructural se obtiene $\mathrm{D}=163.2^{\circ}, \mathrm{I}=-30.1^{\circ}(\mathrm{k}$ $=50.7$ y $\alpha 95=17.5^{\circ}$; Figura $5 \mathrm{e}$, Tabla 1 ).

4.6. Unión de las zonas este y sur (Panalillo y Graben de Bledos).

Cada una de las zonas Panalillo y Graben de Bledos tienen pocos datos pero dan direcciones muy similares; geográficamente son zonas cercanas y están en un dominio tectónico diferente a las otras regiones (Figura 1). Se consideró razonable hacer un análisis unificado de las dos zonas. Combinando los sitios se obtiene la dirección in situ $\mathrm{D}=160.1^{\circ}, \mathrm{I}=-30.5^{\circ},\left(\mathrm{k}=104.6, \alpha 95=5.9^{\circ}, \mathrm{N}=7\right)$, que corregida corresponde a $\mathrm{D}=161.5^{\circ}, \mathrm{I}=-29.5^{\circ},(\mathrm{k}=108.0$ y $\left.\alpha 95=5.8^{\circ}\right)$.

\subsection{Zona sureste (El Naranjero- San Diego)}

En esta zona se muestrearon dos sitios, uno cerca de San Diego de la Unión (sitio P22) y otro en El Naranjero (sitio P33). De estos dos sitios solamente en P22 se pudo obtener una dirección característica. En algunos de los especímenes no fue posible definir de manera clara la componente primaria en los diagramas ortogonales, por lo que se utilizó la técnica de círculos mayores (Kirschvink, 1980) para determinar una dirección característica (Figura $4 \mathrm{j}$ ), siendo ésta de carácter reverso, inclinación alta y parámetros estadísticos pobres (Tabla 1). El sitio P33 muestra un comportamiento completamente errático por lo que también se desechó (Figura 4k).

4.8. Análisis integral de todos los sitios de la Ignimbrita Panalillo Superior

El análisis paleomagnético muestra que en todas las muestras la MC es reversa, siendo que las direcciones medias de sitio varían ligeramente en declinación entre $148.1^{\circ}$ y $175.9^{\circ}$, mientras la inclinaciones oscilan entre $-18.3^{\circ}$ y $-48.0^{\circ}$ (Figura 6 ). Al analizar las direcciones por zonas, se aprecia que la variación de declinación es entre $156.4^{\circ}$ y $162.8^{\circ}$, con una mayor variación de la inclinación entre $-22.9^{\circ}$ y $-36.6^{\circ}$. Las direcciones medias en Valle Umbroso, Mexquitic y el combinado de la zona este-sur

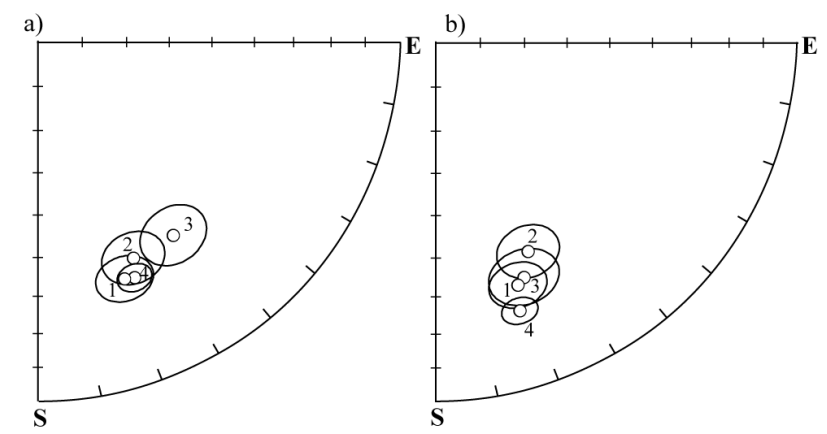

Figura 6. Comparación de las medias de las zonas estudiadas in situ (a) y realizando corrección estructural (b). 1) Combinado Panalillo-Graben de Bledos 2) NW o La Pendencia, 3) Centro norte o Ahualulco-Mexquitic, 4) Norte o Valle Umbroso.

son estadísticamente indistinguibles con $95 \%$ de confianza, formando un grupo relativamente compacto. Sin embargo, la dirección media del área La Pendencia es estadísticamente distinta de la dirección media en Valle Umbroso. Las direcciones medias de La Pendencia y el resto de las zonas se distinguen principalmente por la mayor inclinación de La Pendencia. La diferencia en inclinación entre las direcciones medias entre La Pendencia y las otras zonas no se explica simplemente en términos de una rotación tectónica con respecto a un eje vertical.

La polaridad reversa en los sitios analizados de la IPS es consistente con un emplazamiento "instantáneo" de esta unidad. No obstante, la diferencia en inclinación entre La Pendencia y las otras zonas sugiere que la unidad litoestratigráfica puede estar formada por depósitos de flujo piroclástico muy similares en litología y aspecto, pero emplazadas en diferente tiempo, aunque ambas durante intervalos de campo inverso. Esto se discute más adelante.

\section{Determinación de mineralogía portadora de la magnetización}

\subsection{Curvas de Histéresis}

Se efectuaron experimentos de histéresis en 18 muestras, al menos dos muestras por zona. Los ciclos de histéresis presentan comportamiento similar; en general con coercitividades bajas, evidenciando la presencia de magnetita (o titanomagnetita). Sin embargo, existen algunas diferencias que permiten dividirlas básicamente en tres tipos.

Las muestras de la zona de Panalillo, P1j, P2d P2f con un ciclo de histéresis angosto, tipo pot-bellied (Tauxe et al., 1996), muestran una componente paramagnética importante. Estos sitios muestran una fuerza coercitiva (Hc) relativamente elevada (hasta $33.6 \mathrm{mT}$ ) y relaciones altas Mrs/Ms de hasta 0.33 (Figura 7a). Las muestras de las zonas Mexquitic, Valle Umbroso, Graben de Bledos, La Pendencia y La Escondida forman ciclos muy 
a)

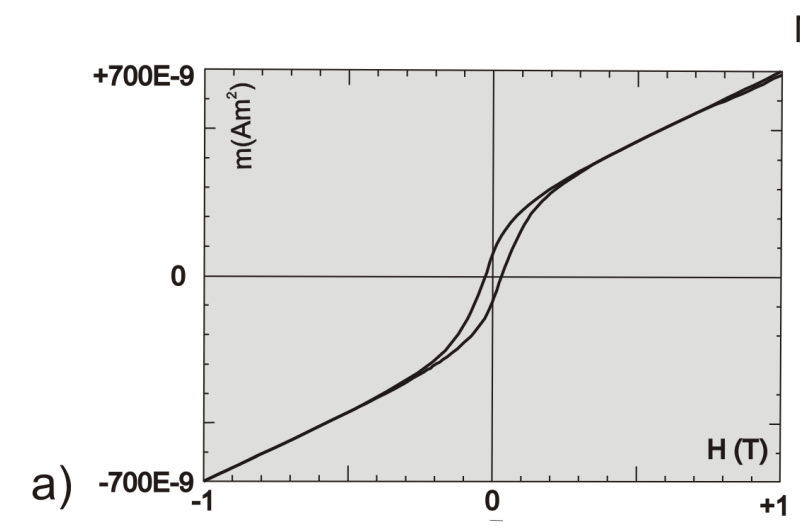

Muestra P1j

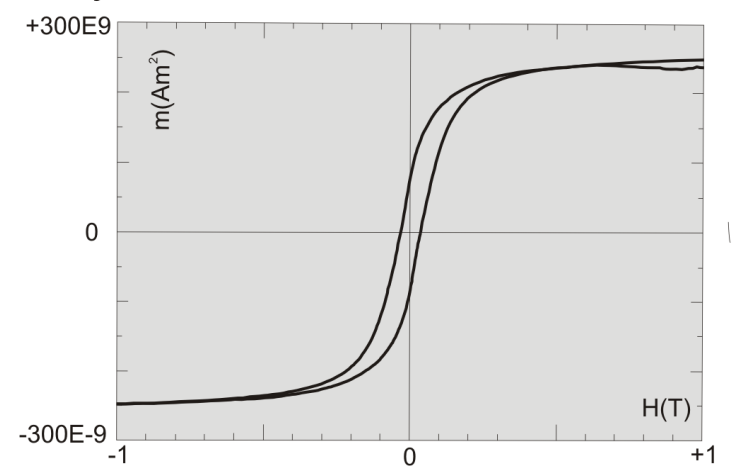

Muestra P11i
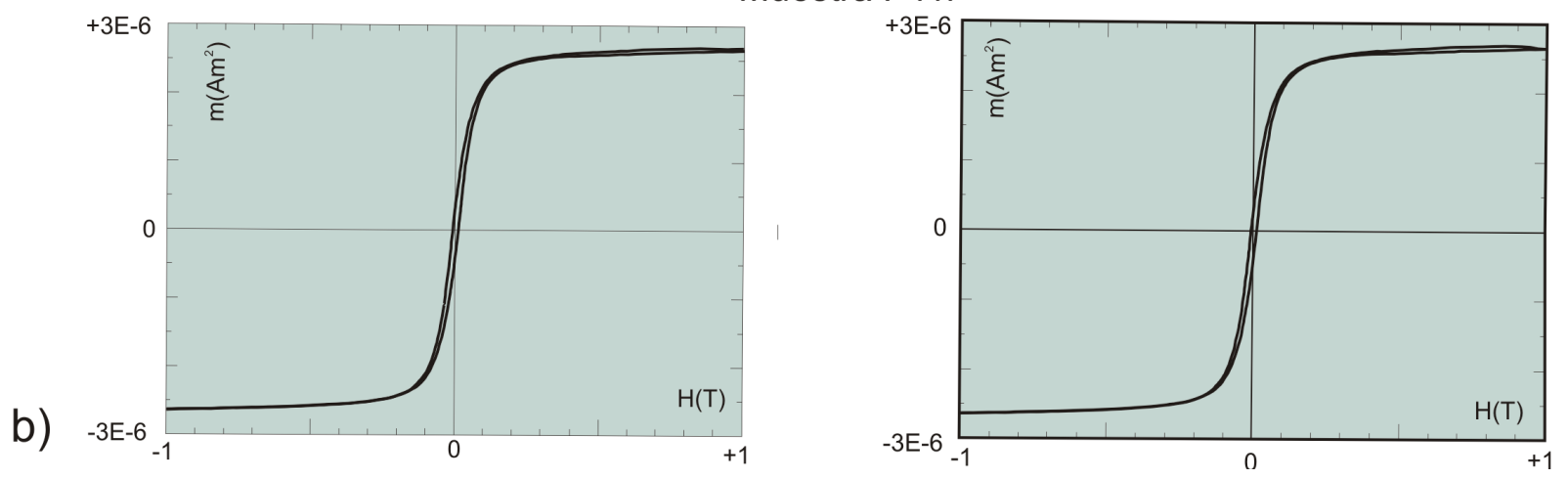

\section{Muestra P33g}

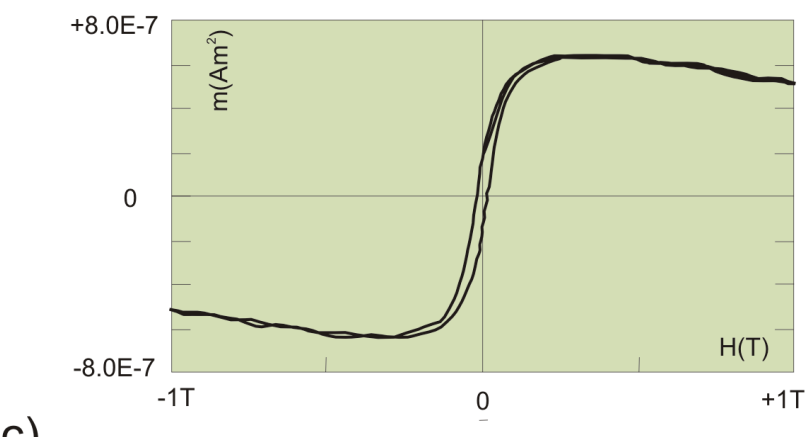

C)

\section{Sin corrección paramagnética}

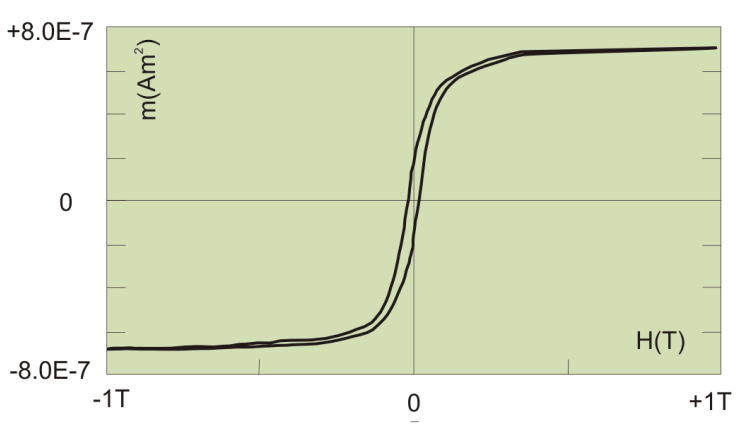

\section{Con corrección paramagnética}

Figura 7. Ciclos de histéresis $\sin /$ con (lado izquierdo/derecho) corrección paramagnética o diamagnética con diferentes comportamientos a) Muestra PAN1J del área Panalillo, que muestra una coercitividad relativamente alta, y con una componente paramagnética importante, b) Muestra PAN11I del área Valle Umbroso, que muestra una coercitividad baja y prácticamente sin componente paramagnética y c) Muestra P33G del área El Naranjero, con coercitividad moderada con una componente diamagnética. $\mathrm{M}=$ campo magnético, $\mathrm{m}=$ momento magnético, $\mathrm{T}=$ Tesla.

angostos como en la muestra P11i (Figura 7b); estos son característicos de minerales de coercitividad baja (entre 8 y $22 \mathrm{mT}$ ) de dominio múltiple (DM). La muestra de la zona El Naranjero (P33g) exhibe un ciclo de histéresis angosto, aunque una coercitividad de remanencia relativamente alta $(\mathrm{Hcr}=36.15 \mathrm{mT})$, pero con una notable componente diamagnética (Figura 7c). La componente diamagnética está probablemente asociada a un contenido alto de sílice en la roca y un contenido bajo de material ferromagnético.

En la gráfica de Day (Figura 8) se puede observar que las muestras se encuentran exclusivamente en el rango de partículas de dominio pseudosencillo; lo cual puede ser el resultado de una mezcla de partículas de dominio sencillo y de dominio múltiple. La relación casi lineal entre coercitividad y la relación Mrs/Ms sugiere que existe una misma población de tamaños de granos de dominio 


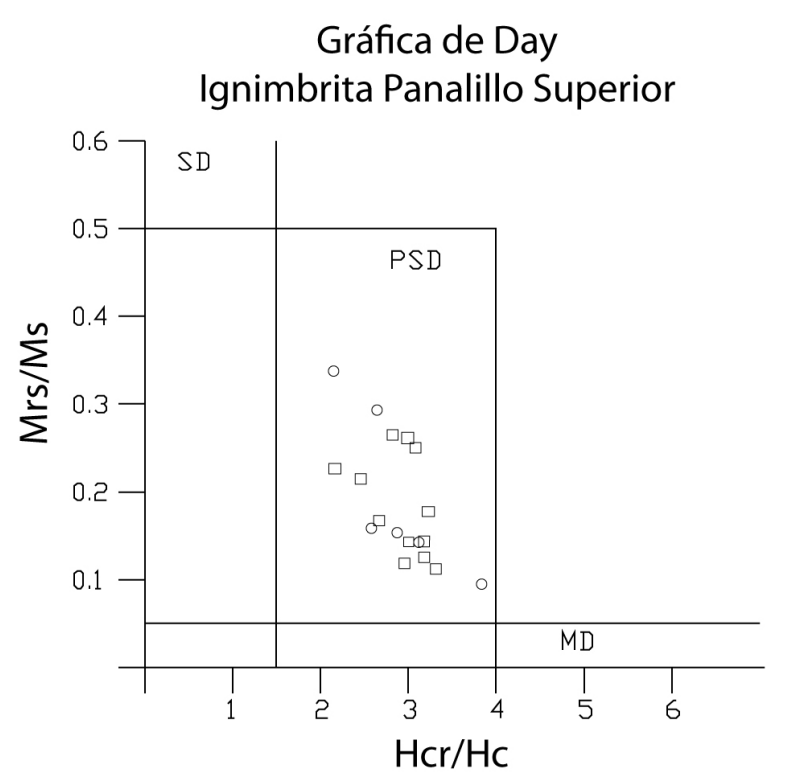

Figura 8.- Gráfica de Day para las muestras de la Ignimbrita Panalillo Superior. El comportamiento general de las partículas es de dominio pseudosencillo, sugiriendo también una mezcla de partículas de dominio múltiple y dominio sencillo.

sencillo a dominio múltiple, pero presentes en diferentes proporciones. Las partículas finas son más abundantes a mayor coercitividad (Figura 9) como lo señalan Dunlop y Özdemir (1997).

\subsection{Magnetización Remanente Isotermal}

La magnetización remanente isotermal (MRI) es un proceso de magnetización que se da en un campo magnetizante fuerte, por la tanto en la naturaleza solo puede darse por descargas eléctricas (rayos), o puede generarse en el laboratorio. Una muestra de magnetita (o titanomagnetita) normalmente alcanzará su saturación antes de las $300 \mathrm{mT}$, mientras que los especímenes de hematita requerirán campos mayores $(>3 \mathrm{~T})$ para poder alcanzar su nivel de saturación.

Algunas muestras de la ignimbrita alcanzaron su nivel de saturación a las $300 \mathrm{mT}$, pero hay otras en que la saturación se alcanzó hasta las $3 \mathrm{~T}$. El ascenso de la adquisición es rápido a bajas inducciones. De estos comportamientos puede inferirse la presencia tanto de magnetita (o titanomagnetita) como de hematita en prácticamente todas las zonas (Figura 10). La contribución de una fase de alta coercitividad (hematita o titanohematita) a la MRI es relativamente menor a $30 \%$ y en aproximadamente $50 \%$ de las muestras es mínima.

\subsection{Susceptibilidad vs. Temperatura}

La susceptibilidad magnética es el grado de magnetización de un material en respuesta a un campo magnético. La susceptibilidad magnética de los minerales
Ignimbrita Panalillo Superior

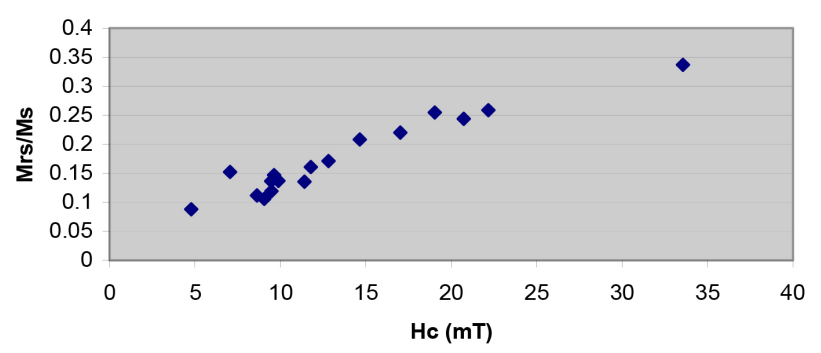

Figura 9.- Relación de magnetización (Mrs/MS) en función de la coercitividad (Hc). Se aprecia una relación lineal muy bien definida. La coercitividad está restringida prácticamente al rango entre 8 y $22 \mathrm{mT}$, sin embargo valores 33.6 ó $4.8 \mathrm{mT}$ se ajustan muy bien a la función, que define de manera precisa la característica de coercitividad de esta roca.

ferromagnéticos varía con la temperatura. La temperatura a la cual la magnetización de saturación desaparece durante el calentamiento, y por lo tanto el comportamiento es paramagnético, es la temperatura de Curie (Tc) o de Néel $\left(\mathrm{T}_{\mathrm{N}}\right)$. A estas temperaturas la energía termal impide el alineamiento de los momentos de los espines. La Tc para la magnetita es de $580{ }^{\circ} \mathrm{C}$ y la $\mathrm{T}_{\mathrm{N}}$ de la hematita es de $675^{\circ} \mathrm{C}$ (Dunlop y Özdemir, 1997). La temperatura de Curie puede aproximarse a partir de mediciones de susceptibilidad $v s$. temperatura.

Se realizaron 19 análisis de susceptibilidad $v s$. temperatura $(\chi-T)$ en muestras de la IPS, correspondientes al mismo número de sitios, obteniéndose un comportamiento muy similar en ocho sitios. Estos se encuentran en las zonas de Mexquitic, Valle Umbroso, Graben de Bledos y La Escondida. El comportamiento de esta curva no es reversible y se describe a continuación.

Durante el calentamiento se aprecia un aumento ligero de la susceptibilidad hacia $\operatorname{los} 200-300^{\circ} \mathrm{C}$, a partir de donde empieza una ligera disminución, que puede sugerir oxidación, aunque el cambio es menor. La susceptibilidad se mantiene constante con un ligero decremento hasta los $570-580{ }^{\circ} \mathrm{C}$ donde se produce el Efecto de Hopkinson, el cual es un aumento súbito de la susceptibilidad justo antes de alcanzar la Tc. En todas las muestras se pone de manifiesto la presencia de magnetita baja en Ti ya que la curva cae abruptamente a $580{ }^{\circ} \mathrm{C}$. Sin embargo, la susceptibilidad no decae completamente a cero, sino que la curva señala que existe un poco de susceptibilidad aún a los $660^{\circ} \mathrm{C}$ que indica la presencia de hematita (Figura 11a y 11b). En el enfriamiento, la susceptibilidad aumenta rápidamente hasta los $580{ }^{\circ} \mathrm{C}$ y después decae ligeramente y se mantiene constante hasta los $50{ }^{\circ} \mathrm{C}$. Sin embargo la susceptibilidad alcanzada durante el enfriamiento es aproximadamente la mitad de la exhibida por la muestra durante el calentamiento, lo que indica que hubo un cambio en la mineralogía original.

Las muestras P33 y P29 de las zonas El Naranjero y La Pendencia, respectivamente (Figura 11c y 11d), muestran un comportamiento similar entre ellas. Durante el 
MRI zona Valle Umbroso

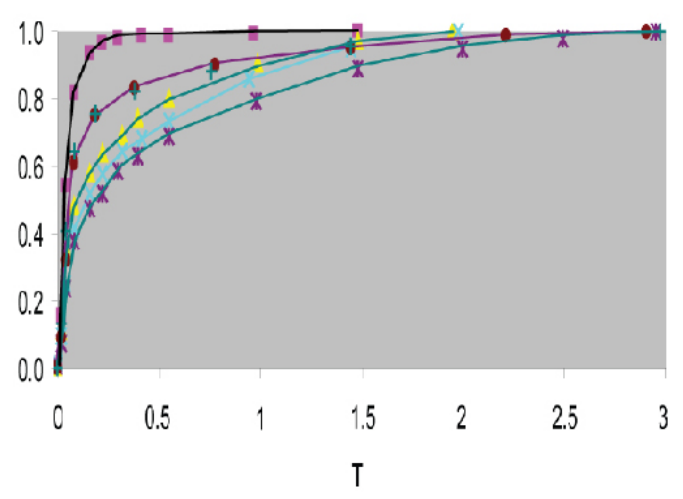

MRI zona Mexquitic
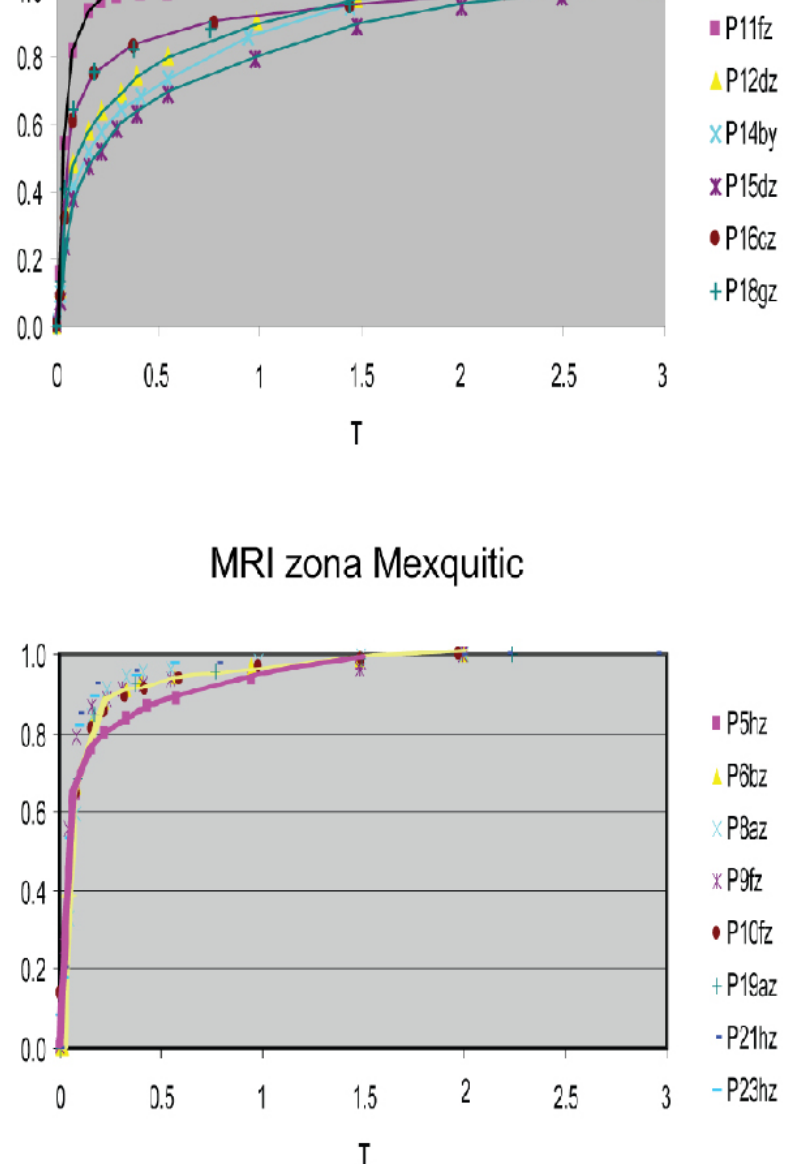

MRI zona Panalillo

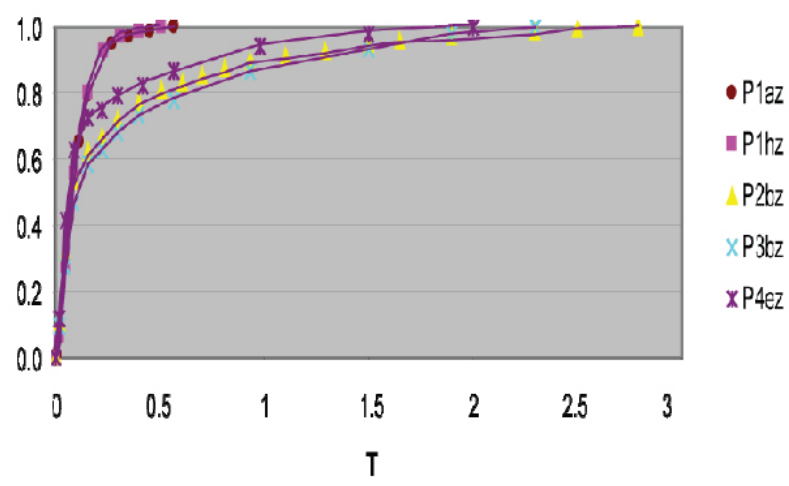

\section{MRI zona La Pendencia}

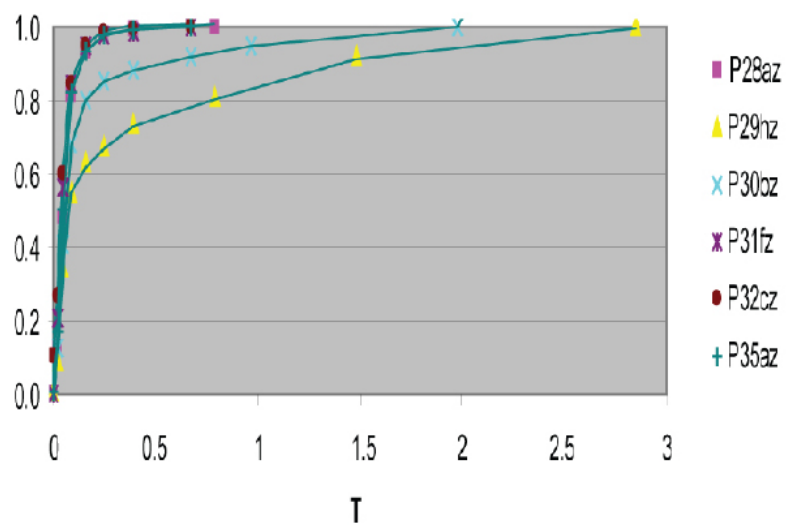

Figura 10. Gráficas de adquisición de MRI de la Ignimbrita Panalillo Superior para las diferentes zonas de estudio (inducción vs. magnetización normalizada). Se pueden observar especímenes que se saturan cerca de las $300 \mathrm{mT}$, indicando la presencia de minerales de baja coercitividad (como magnetita), pero también existen otros que saturan hasta las $3 \mathrm{~T}$, lo que indica la presencia de minerales de alta coercitividad (como hematita) como portadores de la mineralización.

calentamiento disminuye paulatinamente la susceptibilidad y al superar la Tc de la magnetita se observa un descenso más pronunciado; sin embargo, en estas curvas no se aprecia el Efecto de Hopkinson. A partir de los $580^{\circ} \mathrm{C}$ la curva muestra un poco de susceptibilidad hasta $\operatorname{los} 670{ }^{\circ} \mathrm{C}$, indicando la presencia de hematita. En la zona La Pendencia se encontró la única muestra con un carácter reversible (P30b), y el comportamiento también indica la presencia de magnetita pura y en menor grado hematita (Figura 11e).

En la zona de Panalillo se presentan las muestras con un comportamiento diferente (Figura 11f), ya que durante el calentamiento la curva sigue una desmagnetización muy constante hasta los $660^{\circ} \mathrm{C}$ sin indicar algún cambio importante que determine la presencia de magnetita. La curva de enfriamiento se mantiene sin un incremento de la susceptibilidad hasta cerca de los $300{ }^{\circ} \mathrm{C}$ en que comienza a subir paulatinamente. Este comportamiento indica la presencia de hematita, la cual es alterada con el proceso de calentamiento, y la magnetita parece insignificante. Esto es consistente con la alta coercitividad observada durante el proceso de desmagnetización.

\subsection{Microscopía}

Se analizaron en el microscopio mineragráfico y electrónico de barrido muestras en secciones pulidas de los sitios P2-P4 (Panalillo), P10 (Mexquitic), P12 (Valle Umbroso), P25 (La Escondida), P26 (Graben de Bledos), P33 (El Naranjero) y P35 (La Pendencia) de forma que se hizo una cobertura preliminar de todas las zonas. En ellas se realizaron mediciones puntuales de dispersión de rayos $\mathrm{X}$. Los minerales opacos en cada muestra son relativamente abundantes, excepto en P33. En general los cristales más comunes son de ilmenita (Figuras 12B y 12C) con inclusiones ocasionales de zircón, titanomagnetita con bajo Ti (Figuras 12B y 12C) ocasionalmente con texturas de exsolución (Figura 12B y 12C), hematita y en menor proporción magnetita pura (Figura 12e y 12f) que presenta 
a)
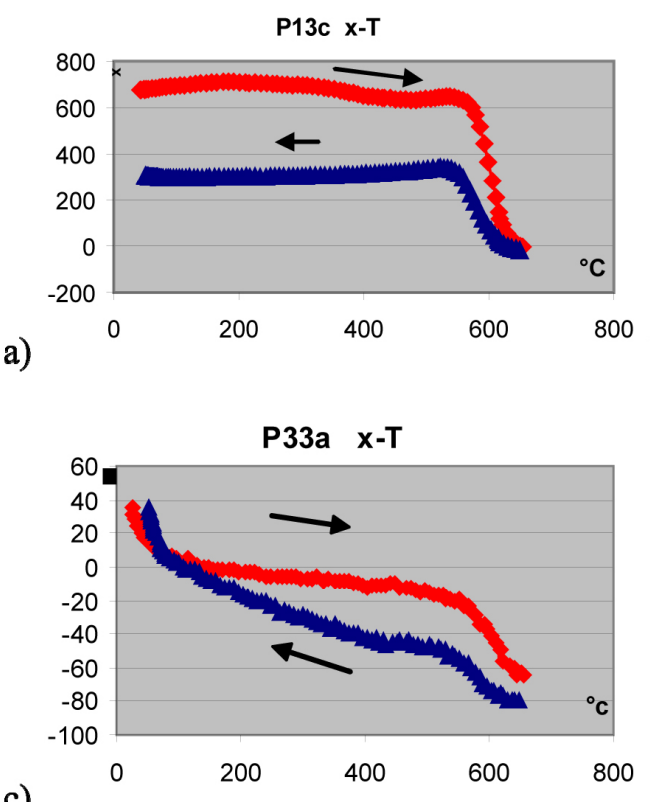

c)

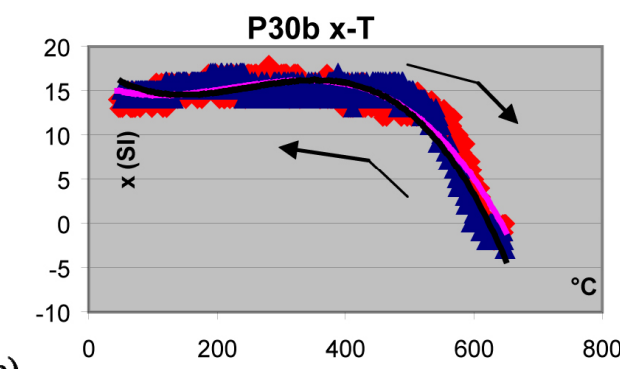

e)

d)
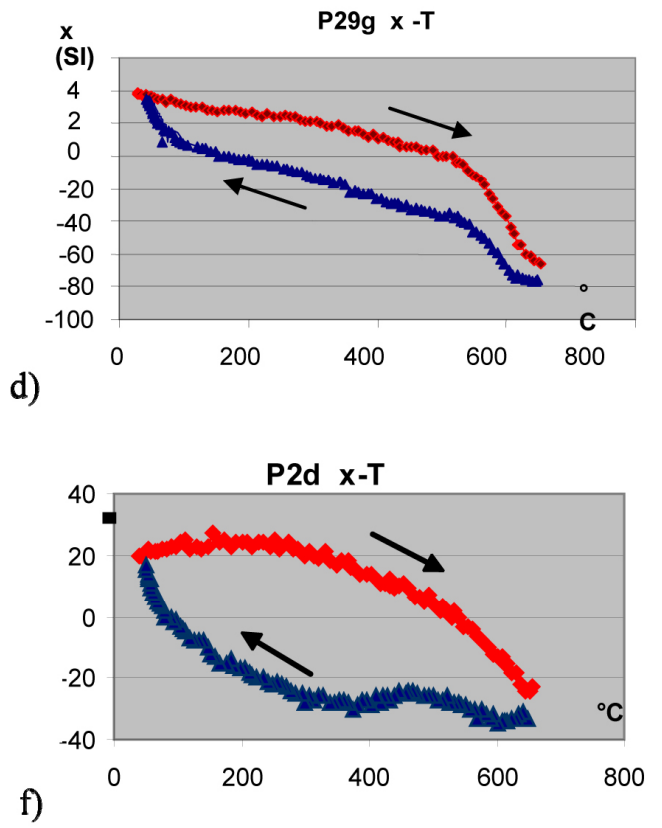

Figura 11. Ejemplos de mediciones de susceptibilidad en función de temperatura para las diferentes zonas. (a) Valle Umbroso, (b) La Pendencia, (c) El Naranjero, (d) y (e) La Pendencia y (f) Panalillo. La escala vertical es arbitraria y representa la susceptibilidad, la escala horizontal es temperatura.

evidencia de oxidación deutérica. La presencia insignificante de óxidos de hierro en P33 es probablemente la causa de la pobre calidad del registro paleomagnético en este sitio.

\section{Geocronología}

En este trabajo se reportan siete fechamientos nuevos. Tres por el método ${ }^{40} \mathrm{Ar} /{ }^{39} \mathrm{Ar}$ en fusión total de cristales individuales de sanidino, efectuados en el laboratorio del Servicio Geológico de Estados Unidos en Reston, Virginia. Cuatro por el método K/Ar en separados de sanidino, los cuales se realizaron en la Universidad de Bretaña Occidental, Francia. Las técnicas de preparación de muestras, análisis de laboratorio y reducción de datos de los análisis de $\mathrm{K}-\mathrm{Ar}$ se pueden consultar en Bellon et al. (1981), y en forma resumida en el Apéndice.

Los métodos de ${ }^{40} \mathrm{Ar} /{ }^{39} \mathrm{Ar}$ se describen de igual manera en el Apéndice. Los resultados analíticos se presentan en la Tabla 2. Las determinaciones arrojan edades que van desde los $26.3 \mathrm{Ma}(\mathrm{K} / \mathrm{Ar})$ hasta $31.3 \mathrm{Ma}\left({ }^{40} \mathrm{Ar} /{ }^{39} \mathrm{Ar}\right)$.
En la Figura 13 se muestran diagramas de probabilidad de edad para los análisis de cristales individuales de sanidino y gráficas de correlación inversa (isócrona inversa). La muestra de ignimbrita (P26), proveniente del Graben de Bledos (Figura 1), dio una edad media ponderada de ${ }^{40} \mathrm{Ar} /{ }^{39} \mathrm{Ar}$ en cristales únicos de sanidino de $28.14 \pm 0.03 \mathrm{Ma}$ que, dentro de los límites de error, es apoyada por la edad de isócrona reportada para los mismos cristales (Figura 13 y Tabla 2). Esta edad media ponderada la interpretamos como la edad de la erupción piroclástica. Cabe destacar la presencia en la muestra de algunos xenocristales de sanidino algo más viejos (contaminantes naturales) que no se emplearon para la obtención de la edad media ponderada. Estos xenocristales provienen de rocas más antiguas y fueron incorporados en la ignimbrita durante el evento explosivo y/o su emplazamiento. Cinco granos de sanidino de una segunda muestra (P36) proveniente del Graben de Bledos (Figura 1) permitieron obtener una edad media ponderada de sanidinos de $28.12 \pm 0.02 \mathrm{Ma}$ (Figura 13). Nótese que estas dos edades ${ }^{40} \mathrm{Ar} /{ }^{39} \mathrm{Ar}$ de muestras de ignimbritas recolectadas en el Graben de Bledos son 

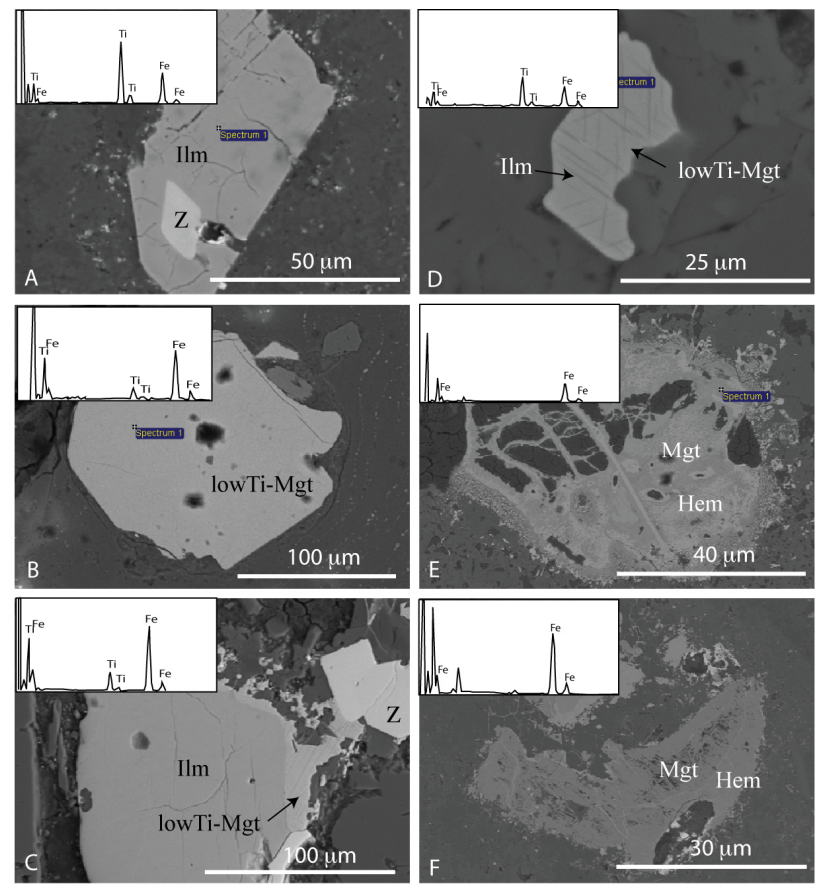

Figura 12. Imagen de electrones retrodispersados y espectros de difracción de rayos X para muestras analizadas con el microscopio electrónico de barrido. (a) Muestra del sitio P12 mostrando cristal anhedral de ilmenita con inclusión de zircón. (b) Muestra del sitio P2 mostrando de un cristal de titanomagnetita euhedral y relativamente homogéneo. (c) Muestra del sitio P35 donde se observa un cristal de ilmenita con sobrecrecimiento de magnetita con bajo Ti con texturas de exsolución. (d) Muestra del sitio P4 donde se observa un cristal de magnetita baja en Ti con textura trellis de exsolución (lamelas de ilmenita). (e) y (f) Cristales de magnetita intensamente oxidados, mostrando hematita en fracturas y en halos rodeando regiones de magnetita (sitios P4 y P10).

indistinguibles dentro de los límites de error reportados $(1 \sigma)$. Por último, cristales de sanidino de la muestra P10 de la zona de Mexquitic permitió calcular una edad media ponderada de $31.28 \pm 0.02$ Ma que también es apoyada por la edad de correlación inversa (Figura 13). Esta edad es significativamente más antigua que las edades reportadas en otras localidades de la IPS (e.g. Labarthe-Hernández et al., 1982 y Tristán-González et al., 2009) y de otras edades obtenidas en esta investigación.

Las edades K-Ar corresponden a un sitio en la zona Valle Umbroso, donde se obtuvo una edad de $28.4 \pm 0.7 \mathrm{Ma}$, y tres edades en la zona noroeste (La Pendencia). Las edades obtenidas en la zona noroeste son $23.6 \pm 0.6,26.4 \pm 0.9$, y $26.3 \pm 0.7 \mathrm{Ma}$ (Tabla 2). Las edades en el área La Pendencia, aun considerando el error analítico son las más jóvenes.

\section{Discusión}

7.1. Panalillo Superior ¿una, dos o más unidades piroclásticas?

El primer fechamiento isotópico (K-Ar roca total) de la IPS (Labarthe-Hernández et al., 1982) reporta una edad de $26.8 \pm 1.3 \mathrm{Ma}$, dato que se cita en muchos trabajos acerca del CVSLP. Sin embargo, Tristán-González et al. (2009) obtuvieron otros tres fechamientos K/Ar (roca total) reportando edades de $25.4 \pm 0.6 \mathrm{Ma}$ en la zona de Ahualulco-Mexquitic, de $28.3 \pm 0.9 \mathrm{Ma}$ en Pinos (cerca de La Pendencia) y de $28.9 \pm 0.5$ Ma para la Sierra de San Miguelito.

Incluyendo los fechamientos presentados en este estudio, apreciamos que las edades obtenidas hasta la fecha están en clara contradicción con la idea de que la IPS está formada por una sola unidad de flujo emplazada de forma instantánea, es decir, durante un único pulso piroclástico. Al menos seis de los doce fechamientos apoyan, dentro de los errores analíticos, la interpretación de un evento eruptivo hace $\sim 28 \mathrm{Ma}$. Esta edad es además el resultado analítico de mayor precisión, pues se basa en fechamientos por el método ${ }^{40} \mathrm{Ar} /{ }^{39} \mathrm{Ar}$ en fusión total de cristales individuales de sanidino. Cuatro fechamientos sugieren la presencia de un evento eruptivo hace $\sim 26.5 \mathrm{Ma}$. Un fechamiento de alta precisión sugiere que un evento eruptivo ocurrió hace $\sim 31 \mathrm{Ma}$. Estos datos analíticos indican que la unidad litoestratigráfica Ignimbrita Panalillo Superior está formada por tres ignimbritas con características litológicas muy similares y que éstas fueron emplazadas en el lapso $\sim 26$ y $31 \mathrm{Ma}$.

Los datos paleomagnéticos obtenidos en las zonas Valle Umbroso, Panalillo, Graben de Bledos y Mexquitic son de menor inclinación, y en el caso de Valle Umbroso estadísticamente diferentes, a la media en La Pendencia. Los datos paleomagnéticos sugieren que existen al menos dos unidades piroclásticas con edades diferentes que han sido cartografiadas como la IPS. La zona de Mexquitic es, aparentemente, una región en donde ambas unidades podrían estar en contacto o mezcladas ya que existe sitios con direcciones similares a La Pendencia (como P5). Sin embargo, los datos paleomagnéticos no tienen la precisión suficiente para demostrar inequívocamente esta interpretación. De igual manera, los dos sitios más orientales de la zona La Pendencia (P37 y P38; Tabla 1) tienen direcciones más afines con la dirección media de Valle Umbroso.

En la Figura 14 se muestra la escala de polaridad geomagnética para el intervalo entre 23.3 y $33.4 \mathrm{Ma}$ (Cande y Kent, 1995) y se grafican los fechamientos publicados y los obtenidos en este estudio. Los fechamientos se agrupan de acuerdo a la polaridad reversa en los períodos de tiempo que estas rocas pudieron haberse emplazado. Existe una mayor frecuencia de fechas tanto para el cron C8r (de 26.554 Ma a 27.027 Ma), así como para el cron C9r (de 27.972 Ma a 28.283 Ma) donde los fechamientos pueden ser correlacionados considerando el error analítico. Igualmente, se muestra una tercera alternativa, basada en el fechamiento ca. $31 \mathrm{Ma}$ en el cron C12r. En la figura 15 se muestra un mapa con la distribución de las fechas obtenidas en este y otros estudios. Las edades no muestran una relación 
Tabla 2. ${ }^{40} \mathrm{Ar} /{ }^{39} \mathrm{Ar}$ Edad de cristales individuales de sanidino por fusión LASER total para muestras de la Ignimbrita Panalillo Superior y edades de K-Ar en concentrados de sanidino.

\begin{tabular}{|c|c|c|c|c|c|c|c|}
\hline $\begin{array}{c}\text { Número de } \\
\text { cristal }\end{array}$ & $\begin{array}{l}{ }^{39} \mathrm{Ar}_{\mathrm{k}} \\
\text { (Moles) }\end{array}$ & $\begin{array}{c}\text { Extracción } \\
\text { Radiogénica (\%) }\end{array}$ & ${ }^{40} \mathrm{Ar}^{*}$ & $\mathrm{~K} / \mathrm{Ca}$ & $\mathrm{K} / \mathrm{Cl}$ & $\begin{array}{l}\text { Edad } \\
(\mathrm{Ma})\end{array}$ & $\begin{array}{l}\text { Error } \\
(\mathrm{Ma})\end{array}$ \\
\hline \multicolumn{2}{|c|}{ P-10 Ignimbrita, S.L.P. } & \multicolumn{2}{|c|}{ cristal individual de sanidino TF } & \multicolumn{2}{|c|}{$J=0.004216 \pm 0.50 \%$} & \multicolumn{2}{|l|}{$\# 176 K D 48$} \\
\hline 3 & $7.24 \mathrm{E}-14$ & 97.4 & 4.143 & 41 & 272 & 31.24 & \pm 0.04 \\
\hline 2 & $5.02 \mathrm{E}-14$ & 99.3 & 4.149 & 40 & 287 & 31.28 & $\pm \mathbf{0 . 0 4}$ \\
\hline 7 & $4.14 \mathrm{E}-14$ & 99.0 & 4.152 & 36 & 234 & 31.31 & \pm 0.08 \\
\hline 6 & $6.69 \mathrm{E}-14$ & 99.1 & 4.152 & 42 & 257 & 31.31 & \pm 0.06 \\
\hline 5 & $6.96 \mathrm{E}-14$ & 99.0 & 4.167 & 36 & 276 & 31.42 & $\pm \mathbf{0 . 0 9}$ \\
\hline 8 & $3.34 \mathrm{E}-14$ & 96.3 & 4.182 & 39 & 230 & 31.53 & \pm 0.09 \\
\hline 4 & $3.05 \mathrm{E}-14$ & 96.7 & 4.182 & 48 & 249 & 31.53 & \pm 0.05 \\
\hline 10 & $4.93 \mathrm{E}-14$ & 97.3 & 4.231 & 34 & 260 & 31.90 & \pm 0.04 \\
\hline \multirow[t]{2}{*}{1} & $2.88 \mathrm{E}-14$ & 99.6 & 4.370 & 32 & 330 & 32.94 & \pm 0.04 \\
\hline & & & & \multicolumn{2}{|c|}{ Edad media ponderada $=$} & $=\begin{array}{r}\mathbf{3 1 . 2 8} \\
(\mathrm{MSWD}=\end{array}$ & $\begin{array}{l} \pm \mathbf{0 . 0 2} \\
0.93, \mathrm{n}=5)\end{array}$ \\
\hline \multirow{12}{*}{$\begin{array}{c}P-26 \quad I g \\
4 \\
11 \\
10 \\
8 \\
3 \\
6 \\
7 \\
2\end{array}$} & ita, S.L.P. & \multicolumn{2}{|c|}{ cristal individual de sanidino TF } & \multicolumn{2}{|c|}{$J=0.004218 \pm 0.50 \%$} & $\# 177 K D 48$ & \\
\hline & $4.28 \mathrm{E}-14$ & 99.1 & 3.754 & 20 & 297 & 28.11 & $\pm \mathbf{0 . 0 6}$ \\
\hline & $2.90 \mathrm{E}-14$ & 96.2 & 3.756 & 22 & 336 & 28.12 & $\pm \mathbf{0 . 0 5}$ \\
\hline & $4.50 \mathrm{E}-14$ & 99.6 & 3.754 & 24 & 267 & 28.17 & \pm 0.04 \\
\hline & $6.03 \mathrm{E}-14$ & 99.5 & 3.724 & 24 & 324 & 28.31 & \pm 0.05 \\
\hline & $4.28 \mathrm{E}-14$ & 99.9 & 3.792 & 22 & 238 & 28.34 & \pm 0.06 \\
\hline & $6.16 \mathrm{E}-14$ & 99.5 & 3.732 & 20 & 285 & 28.35 & \pm 0.05 \\
\hline & $4.85 \mathrm{E}-14$ & 99.7 & 3.779 & 23 & 303 & 28.36 & \pm 0.05 \\
\hline & $4.01 \mathrm{E}-14$ & 98.7 & 3.723 & 22 & 270 & 28.38 & \pm 0.05 \\
\hline & $4.66 \mathrm{E}-14$ & 99.2 & 3.750 & 22 & 274 & 28.53 & \pm 0.05 \\
\hline & $6.01 \mathrm{E}-14$ & 97.5 & 3.759 & 27 & 238 & 28.63 & \pm 0.04 \\
\hline & & & & \multicolumn{2}{|c|}{ Edad media ponderada $=$} & $=\begin{array}{r}\mathbf{2 8 . 1 4} \\
(\mathrm{MSWD}=\end{array}$ & $\begin{array}{l} \pm \mathbf{0 . 0 3} \\
0.57, \mathbf{n}=3)\end{array}$ \\
\hline \multirow{11}{*}{$\begin{array}{c}\text { P-36 Ignim } \\
10 \\
3 \\
9\end{array}$} & ita, S.L.P. & \multicolumn{2}{|c|}{ cristal individual de sanidino TF } & \multicolumn{2}{|c|}{$J=0.004255 \pm 0.50 \%$} & $\# 178 K D 48$ & \\
\hline & $3.20 \mathrm{E}-14$ & 98.3 & 3.723 & 23 & 253 & 27.84 & $\pm \mathbf{0 . 0 8}$ \\
\hline & $4.84 \mathrm{E}-14$ & 98.9 & 3.729 & 24 & 280 & 28.05 & $\pm \mathbf{0 . 0 4}$ \\
\hline & $6.04 \mathrm{E}-14$ & 98.0 & 3.768 & 22 & 323 & 28.07 & $\pm \mathbf{0 . 0 4}$ \\
\hline & $3.80 \mathrm{E}-14$ & 98.0 & 3.775 & 24 & 287 & 28.14 & $\pm \mathbf{0 . 1 1}$ \\
\hline & $5.76 \mathrm{E}-14$ & 99.7 & 3.713 & 22 & 345 & 28.16 & $\pm \mathbf{0 . 0 8}$ \\
\hline & $7.11 \mathrm{E}-14$ & 95.7 & 3.876 & 19 & 309 & 28.21 & \pm 0.04 \\
\hline & $7.10 \mathrm{E}-14$ & 97.5 & 3.813 & 24 & 297 & 28.28 & \pm 0.07 \\
\hline & $6.22 \mathrm{E}-14$ & 97.2 & 3.830 & 23 & 265 & 28.31 & \pm 0.04 \\
\hline & $7.16 \mathrm{E}-14$ & 98.0 & 3.820 & 23 & 334 & 28.47 & \pm 0.04 \\
\hline & & & & \multicolumn{2}{|c|}{ Edad media ponderada $=$} & $\begin{array}{r}\mathbf{2 8 . 1 2} \\
(\mathrm{MSWD}=\mathbf{2}\end{array}$ & $\begin{array}{l} \pm \mathbf{0 . 0 2} \\
2.13, \mathrm{n}=5)\end{array}$ \\
\hline \multirow[t]{2}{*}{ Muestra } & $\operatorname{Edad} \pm 1 \rrbracket$ & Fracci-n & ${ }^{40} \mathrm{Ar}_{\mathrm{R}}$ & $\%$ 40ArR & $\mathrm{K}_{2} \mathrm{O}(\mathrm{wt} \%)$ & Peso (g) & \\
\hline & & & (10-6 cm3/g) & & & & \\
\hline PAN9 & $28.4 \pm 0.7$ & $\mathrm{f}$ & 4.9 & 65.7 & 5.31 & 0.1535 & \\
\hline P4 & $23.6 \pm 0.6$ & $\mathrm{f}$ & 7.17 & 64.1 & 9.36 & 0.1529 & \\
\hline P3 & $26.4 \pm 0.9$ & $*$ & & & & & \\
\hline P5 & $26.3 \pm 0.7$ & $*$ & & & & & \\
\hline
\end{tabular}

Las edades en negritas son las utilizadas para calcular la edad media. TF=Fusión total.

$\pm 1 \sigma$ calculado siguiendo la ecuación de Cox y Dalrymple (1967).

Fracción; RE, roca entera; m, matriz; f, feldespato; bi, biotita.

wt. \%; por ciento en peso de potasio.

* Comunicación personal Alfredo Aguillón Robles, 2008

geográfica clara, pero las edades $c a .26$ Ma se concentran en el área La Pendencia, al noroeste, y las edades $c a .28$ Ma se encuentran principalmente en las zonas centro, oriente y sur.

En su conjunto, los fechamientos radiométricos sugieren que puede haber hasta cuatro unidades de flujo diferentes en la IPS, pero la confiabilidad de los resultados del sistema $\mathrm{K}-\mathrm{Ar}$ puede ser disputada por la presencia de líticos y cristales accidentales que introducen $\mathrm{K}$ ó Ar extraños a los análisis. Los diagramas de dispersión de la Figura 13 contienen más de una población de edades, lo que sugiere que la ignimbrita contiene cristales de sanidino accidentales hasta dos millones de años más antiguos que la edad de emplazamiento interpretada. Es razonable sugerir que los análisis de $\mathrm{K}-\mathrm{Ar}$ son menos precisos que los de ${ }^{40} \mathrm{Ar} /{ }^{39} \mathrm{Ar}$. Sin embargo, la edad ca. 26.5 Ma no se puede explicar por la presencia de sanidinos accidentales. 

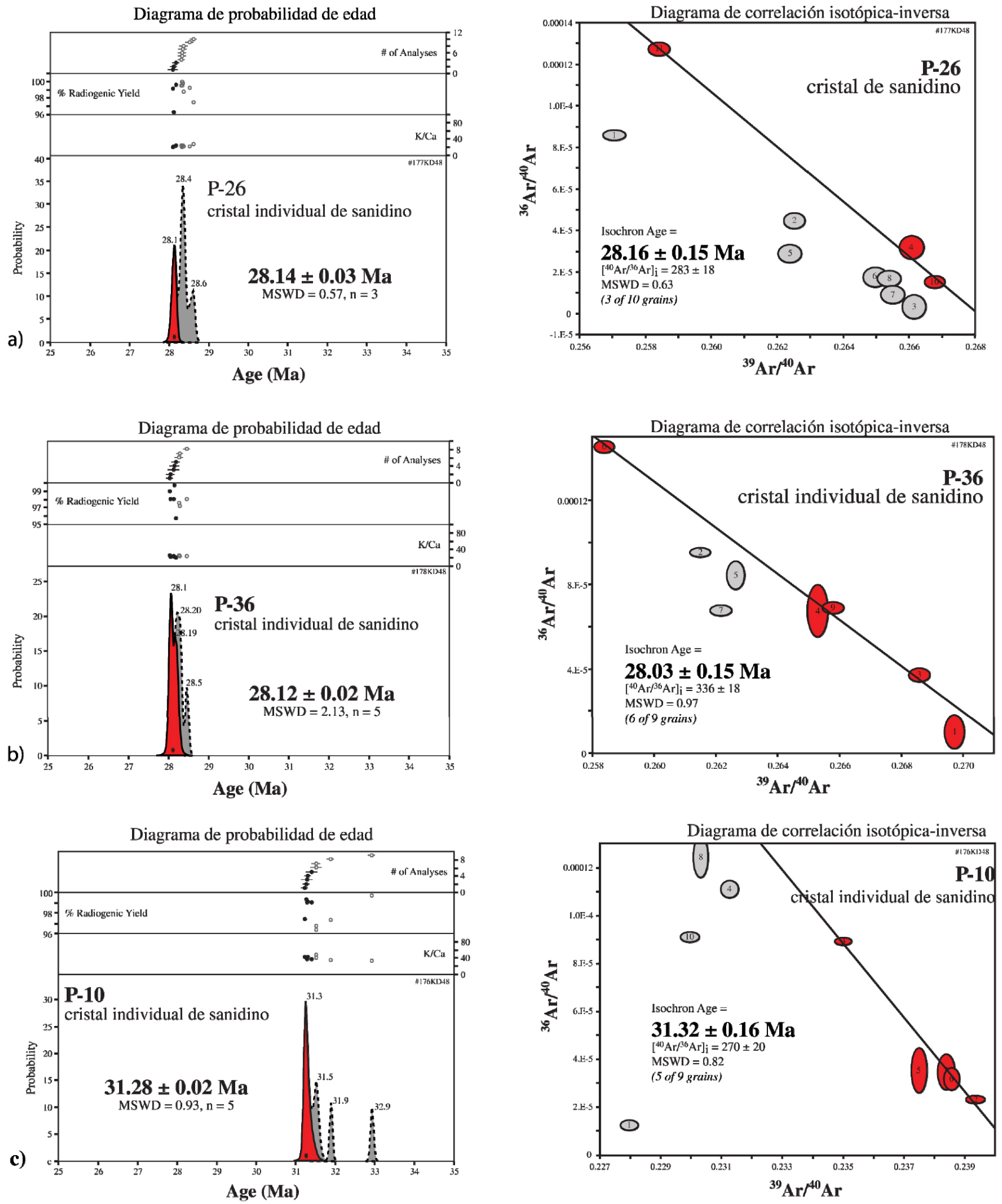

Figura 13. Representación gráfica de datos de ${ }^{40} \mathrm{Ar} /{ }^{39} \mathrm{Ar}$ obtenidos por la técnica de fusión total por láser de cristales individuales de sanidino en tres muestras (P26, P36 y P10) de la Ignimbrita Panalillo Superior. La columna de la izquierda ilustra los diagramas de probabilidad de edad. Las gráficas de la derecha son diagramas de correlación isotópica inversa. Todos los datos son graficados con el mismo nivel de precisión de $1 \sigma$. Las coordenadas geográficas de los sitios de muestreo se indican en la Tabla 1. 


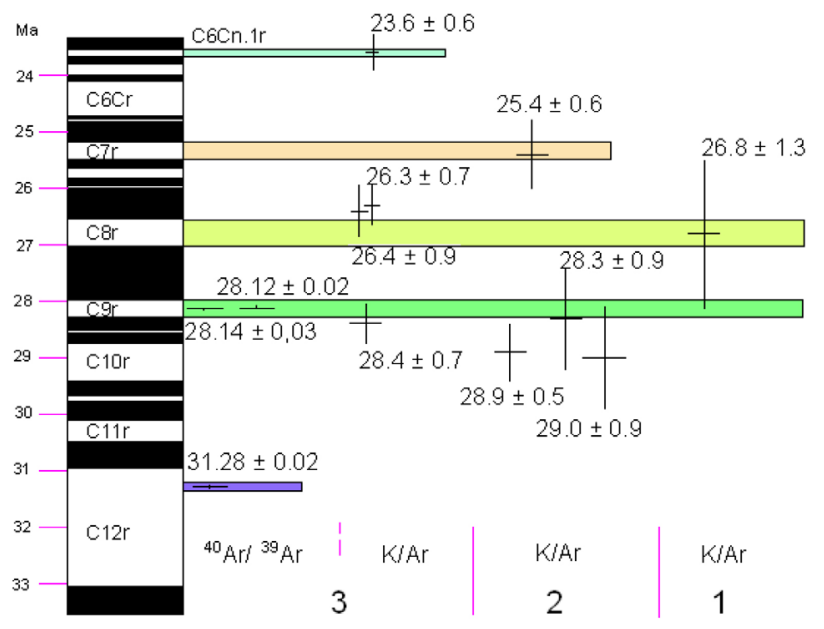

Figura 14. Parte de la escala de polaridad magnética de Cande y Kent (1995), donde se ubican los fechamientos isotópicos de la ignimbrita Panalillo Superior. La escala de tiempo indica la polaridad del campo magnético, siendo normal los intervalos mostrados en negro y reversa en los blancos. Las barras horizontales indican correspondencia entre los fechamientos y eventos eruptivos probables en que se expulsaron los derrames piroclásticos. Referencias: 1) Labarthe-Hernández et al., 1982; 2) Tristán-González et al., 2009; 3) este trabajo
La edad de ${ }^{40} \mathrm{Ar} /{ }^{39} \mathrm{Ar}$ de $\sim 31$ Ma para la IPS está en contradicción aparente con la estratigrafía regional, ya que la unidad subyacente (Ignimbrita Cantera) ha sido fechada en $29.0 \pm 1.5 \mathrm{Ma}$ una muestra de la IPS en esta área ha sido fechada en $25.4 \pm 0.6 \mathrm{Ma}$ (Tristán-González et al., 2009). Un trabajo más detallado es necesario para establecer el significado de la edad $c a$. $31 \mathrm{Ma}$, pero con base en los resultados presentados es razonable concluir que en la zona de Mexquitic hay una ignimbrita más antigua con las características litológicas de la IPS, y además la dirección paleomagnética del sitio $\mathrm{P} 10\left(\mathrm{D}=148.1^{\circ}, \mathrm{I}=-27.8^{\circ}\right)$ no se asemeja claramente a las direcciones de Valle Umbroso o La Pendencia; sin embargo, el dato proviene de un solo sitio. Finalmente, si un examen detallado de la IPS muestra que esta formación con litología característica no corresponde a un solo evento eruptivo, no existe una razón a priori para suponer que la Ignimbrita Cantera también sea producto de un solo flujo piroclástico (Torres-Hernández, 2009).

\subsection{Rotaciones y Anomalías de Inclinación}

Existen diferentes métodos paleomagnéticos para calcular el movimiento de un bloque, ya sea una rotación

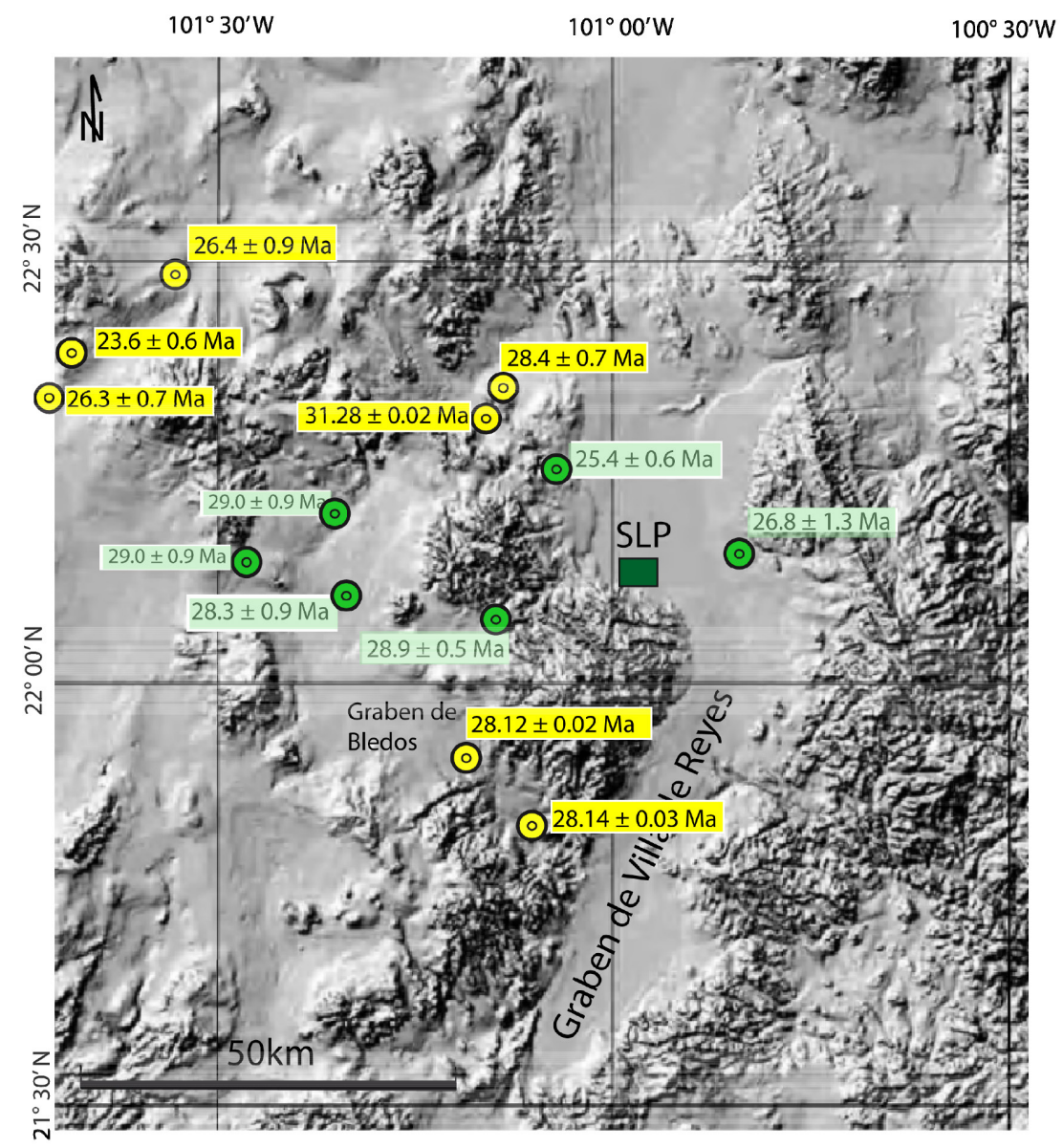

Figura 15. Modelo digital de elevación de la zona de estudio mostrando la ubicación de las muestras fechadas en la Ignimbrita Panalillo Superior. Los sitios en amarillo corresponden a los realizados en este estudio y en verde aquellos tomados de la literatura. 
respecto a un eje vertical, un desplazamiento puramente latitudinal, o un movimiento libre sobre la esfera. Un método sencillo calcula la anomalía de inclinación $\mathrm{F}$ y la rotación $\mathrm{R}$, además de los errores asociados (Butler, 1998). La dirección esperada $(I x, D x)$, calculada a partir del polo de referencia para el cratón, es simplemente comparada con la dirección paleomagnética observada $(I o, D o)$. $F$ está dada por: $F=$ $I x-I o$, y la rotación $R$ está dada por: $R=D o-D x$. $R$ es definida como positiva cuando $D o$ es en el sentido de las manecillas del reloj de $D x$.

\subsubsection{Polo de Referencia}

Para América del Norte la curva de vagabundeo polar aparente (CVPA) está basada en polos determinados en lugares y en unidades que se consideran estables por no haber sido afectados por deformaciones tectónicas. En este trabajo se ha utilizado la curva propuesta por Besse y Courtillot (2002), en la que hacen un cálculo de los paleopolos cada $5 \mathrm{Ma}$. De acuerdo a los fechamientos obtenidos para el CVSLP la actividad magmática debió ocurrir en algún tiempo entre los 26 y $34 \mathrm{Ma}$. Para realizar los cálculos de paleopolos se utilizaron las coordenadas de un punto central del área de estudio en $101.0^{\circ} \mathrm{W}-22.3^{\circ} \mathrm{N}$ para los sitios de las zonas Valle-Umbroso, Mexquitic y este-sur; y $101.4^{\circ} \mathrm{W}-22.4^{\circ} \mathrm{N}$ para la zona La Pendencia. El paleopolo de referencia utiliza los datos de Besse y Courtillot (2002) para 30 Ma y está localizado en: $79.6^{\circ} \mathrm{N}$ $187.9^{\circ} \mathrm{E}$.

\subsubsection{Direcciones medias para la Ignimbrita Panalillo Superior}

Con base en el análisis de los fechamientos radiométricos y el estudio paleomagnético, se calculó una dirección media para la IPS que combina los resultados de Valle Umbroso, Mexquitic, Graben de Bledos y la zona Panalillo. Esta dirección, corregida estructuralmente es de $\mathrm{N}=21$, D $=160.5^{\circ}, \mathrm{I}=-27.7^{\circ},\left(\mathrm{k}=99.4\right.$ y $\left.\alpha 95=3.2^{\circ}\right)$; esta media indica un polo paleomagnético virtual $70.7^{\circ} \mathrm{N}-149.0$ ${ }^{\circ} \mathrm{E}\left(\mathrm{dp}=1.9^{\circ}, \mathrm{dm}=3.5^{\circ}\right)$. El ejercicio de combinar 21 sitios con diferentes actitudes estructurales muestra que el parámetro de precisión aumenta de 72.6 (in situ) a 99.4 (corregido estructuralmente), lo que sugiere - aunque no demuestra - que la magnetización es anterior al fallamiento. La comparación de declinaciones de las direcciones medias para las zonas Valle Umbroso, Mexquitic, Panalillo y Graben de Bledos sugiere que de haber existido una deformación que produjera rotación relativa entre las cuatro zonas, esta rotación es de menor magnitud que la resolución con que puede definirse la dirección media de la ignimbrita $\left(<\sim 6^{\circ}\right)$. La zona La Pendencia indica un polo virtual $68^{\circ} \mathrm{N}-167.8$ ${ }^{\circ} \mathrm{E}\left(\mathrm{dp}=4.4^{\circ}, \mathrm{dm}=7.6^{\circ}\right)$, pero consideramos apropiado excluir los sitios P37 y P38, en el extremo oriental del área, por su posible correlación con la zona Valle Umbroso. Así obtenemos una dirección media para la zona La Pendencia de $\mathrm{D}=158.8^{\circ}, \mathrm{I}=-38.1^{\circ},\left(\mathrm{k}=84.13, \alpha 95=5.6^{\circ}, \mathrm{N}=8\right.$; Tabla 3) con la que se determinó un polo virtual ubicado en $70.3^{\circ} \mathrm{N}-169.7^{\circ} \mathrm{W}\left(\mathrm{dp}=3.9^{\circ}, \mathrm{dm}=6.7^{\circ}\right)$.

\subsubsection{Dirección media para el Campo Volcánico San Luis Potosí y comparación con Norte América.}

La IPS provee, de acuerdo al análisis anterior, solamente dos polos virtuales. Sin embargo, existen datos paleomagnéticos en la literatura para otras unidades del CVSLP (Andreani, 2008; Aranda-Gómez et al., 2007; Tabla 3). Se realizó el ejercicio de agrupar los resultados de una misma unidad reportados por otros autores (que como la Ignimbrita Panalillo representan polos virtuales) y se recalculó la dirección media. Para la Ignimbrita Cantera incluimos los resultados de dos sitios en el Graben de Bledos obtenidos en este estudio. No se combinan con los datos reportados por Andreani (2008) porque son de polaridad normal, a diferencia de los obtenidos por Andreani de polaridad reversa indicando que se trata de dos ignimbritas diferentes.

El conjunto incluye entonces un total de 17 polos virtuales o spot-readings (Tabla 3; Figura 16). Se realizó la prueba de antipodalidad para determinar la confiabilidad del conjunto de datos y se obtuvo una prueba positiva de tipo A, con un ángulo entre direcciones normal y reversa de $1.5^{\circ}$ (McFadden y McElhinny, 1990). La dirección media para el CVSLP está basada entonces en 17 observaciones instantáneas. Esta dirección es de Dec $=341.2^{\circ}$ e Inc $=$ $35.4^{\circ}\left(\mathrm{k}=25.0, \alpha 95=7.3^{\circ}\right)$. Asumiendo la distribución de 17 polos virtuales se calculó el paleopolo del CVSLP en $72.1^{\circ} \mathrm{N}$ y $165.5^{\circ} \mathrm{E}$ (Tabla 3 ); con base en este paleopolo se calculó una dirección media y los parámetros de rotación y aplanamiento (flattening) para $30 \mathrm{Ma}$, obteniéndose así una rotación de $-7.9^{\circ} \pm 9.6^{\circ}$ en el sentido contrario a las manecillas del reloj, y una diferencia de inclinación -8.0 $\pm 11.6^{\circ}$. En ambos casos, los valores obtenidos no son estadísticamente significativos (Tabla 3, Figura 17).

El significado de una rotación que no es estadísticamente significativa es difícil de interpretar. En principio indica que si existe una rotación, ésta es de una magnitud tal que la calidad de los datos paleomagnéticos no permite reconocerla. Por parsimonia, también debe interpretarse como evidencia de que no ha existido rotación. Una de las conclusiones importantes de estudios detallados del contexto estructural del CVSLP es que está afectado por fallamiento complejo (Aranda-Gómez et al., 2007; Xu et al., 2004). En la mayoría de los sitios muestreados, por nosotros y por otros investigadores, el buzamiento de las capas es hacia el NE. Este buzamiento es producto del fallamiento normal. Un ejercicio simple permite demostrar que una ligera inclinación del eje de rotación de las capas de unos $10^{\circ}$ al sur (equivalente a una combinación de dos eventos de fallamiento), o dicho de otra manera: dos eventos de fallamiento concatenados que resultan en un eje de rotación que no es horizontal sino que buza ligeramente inclinado al sur, reduce $\sim 2^{\circ}$ la rotación paleomagnéticamente estimada. Esto sugiere que la rotación estimada de $7.9^{\circ}$ (Figura 17) puede tener una componente aparente (MacDonald, 1980). 
Tabla 3. Resumen de datos paleomagnéticos para el Campo Volcánicos de San Luis Potosí

\begin{tabular}{|c|c|c|c|c|c|c|c|c|c|c|}
\hline \multirow{2}{*}{ Unidad } & \multicolumn{5}{|c|}{ Direcciones paleomagnéticas } & \multirow{2}{*}{ polaridad } & \multicolumn{2}{|c|}{ Coord. Polo } & \multirow{2}{*}{ edad } & \multirow{2}{*}{ referencia } \\
\hline & $\mathbf{N}$ & $\mathrm{Dg}$ & $\lg$ & $\boldsymbol{k}$ & $\alpha 95$ & & Lat( $\left.{ }^{\circ} \mathrm{N}\right)$ & Lon $\left({ }^{\circ} \mathrm{E}\right)$ & & \\
\hline \multicolumn{11}{|c|}{ Campo Volcánico San Luis Potosí } \\
\hline Panalillo1 & 21 & 161.3 & -27.7 & 99.4 & 3.2 & $r$ & 70.7 & 149.0 & $28.1 \mathrm{Ma}$ & Este estudio \\
\hline Panalillo2 & 8 & 158.8 & -38.1 & 84.1 & 5.6 & $r$ & 70.3 & 169.7 & $26.5 \mathrm{Ma}$ & Este estudio \\
\hline Cantera1 & 7 & 165.3 & -22.7 & 58.8 & 7.7 & $r$ & 72.7 & 135.4 & $29 \mathrm{Ma}$ & Andreani (2008) \\
\hline Cantera2 & 2 & 341.8 & 46.4 & & & $\mathrm{n}$ & 72.5 & 192.2 & $29 \mathrm{Ma} ?$ & Este estudio \\
\hline Portezuelos & 5 & 166.9 & -42.0 & 20.2 & 15.3 & $\mathrm{r}$ & 77.8 & 182.1 & $30.6 \mathrm{Ma}$ & Andreani (2008) \\
\hline San Miguelito & 3 & 156.5 & -38.4 & 41.5 & 19.4 & $\mathrm{r}$ & 68.2 & 171.2 & $30 \mathrm{Ma}$ & Andreani (2008) \\
\hline Santa María & 2 & 156.6 & -20.8 & & & $\mathrm{r}$ & 64.4 & 146.8 & Oligo & Andreani (2008) \\
\hline Peaje & 1 & 167.4 & -22.7 & 186.6 & 4.4 & $\mathrm{r}$ & 73.9 & 129.4 & $37-30 \mathrm{Ma}$ & Andreani (2008) \\
\hline Ojo Caliente & 3 & 157.2 & -50.0 & 9.7 & 42.1 & $\mathrm{r}$ & 67.7 & 197.6 & Oligo & Andreani (2008) \\
\hline Zapote & 1 & 349.8 & 32.8 & 43.4 & 9.3 & $\mathrm{n}$ & 79.6 & 148.5 & 27 & Andreani (2008) \\
\hline Cabras & 1 & 14.4 & 47.9 & 41.5 & 14.4 & $\mathrm{n}$ & 76.6 & 337.5 & $<26.6$ & Andreani (2008) \\
\hline Los Castillos & 1 & 147.8 & -58.7 & 139.0 & 4.2 & $\mathrm{r}$ & 57.4 & 208.9 & Oligo & Andreani (2008) \\
\hline Indeterminada & 1 & 329.3 & 40.2 & 20.6 & 14.9 & $\mathrm{n}$ & 61.7 & 171.3 & Oligo & Andreani (2008) \\
\hline Indeterminada & 1 & 306.2 & 40.7 & 43.4 & 9.3 & $\mathrm{n}$ & 40.6 & 181.4 & Oligo & Andreani (2008) \\
\hline Las Pilas & 1 & 352.6 & 14.6 & 650.2 & 3.0 & $\mathrm{n}$ & 73.3 & 104.9 & Oligo & Aranda-Gómez et al. (2007) \\
\hline Pinos 1 & 1 & 336.7 & 25.8 & na & & $\mathrm{n}$ & 66.2 & 150.7 & Oligo & Aranda-Gómez et al. (2007) \\
\hline Pinos 2 & 1 & 344.7 & 21.7 & na & & $\mathrm{n}$ & 71.6 & 133.4 & Oligo & Aranda-Gómez et al. (2007) \\
\hline Normal & 8 & 342.0 & 35.0 & 17.5 & 13.6 & & & & & \\
\hline Reversa & 9 & 160.4 & -35.8 & 33.3 & 9.0 & & & & & \\
\hline Global & 17 & 341.2 & 35.4 & 25.0 & 7.3 & & 72.1 & 165.5 & $(K=228.2 ;$ & ; $\left.\mathrm{A} 95=6.8^{\circ}\right)$ \\
\hline
\end{tabular}

Dg e Ig son la declinación e inclinación observadas, con sus respectivos parametros estadísticos ( $\mathrm{k}$ y $\alpha 95)$ cuando hay más de tres observaciones corresponde al promedio y de otra manera a los resultados reportados.

Lat y Lon son las coordenadas del polo virtual correspondiente.

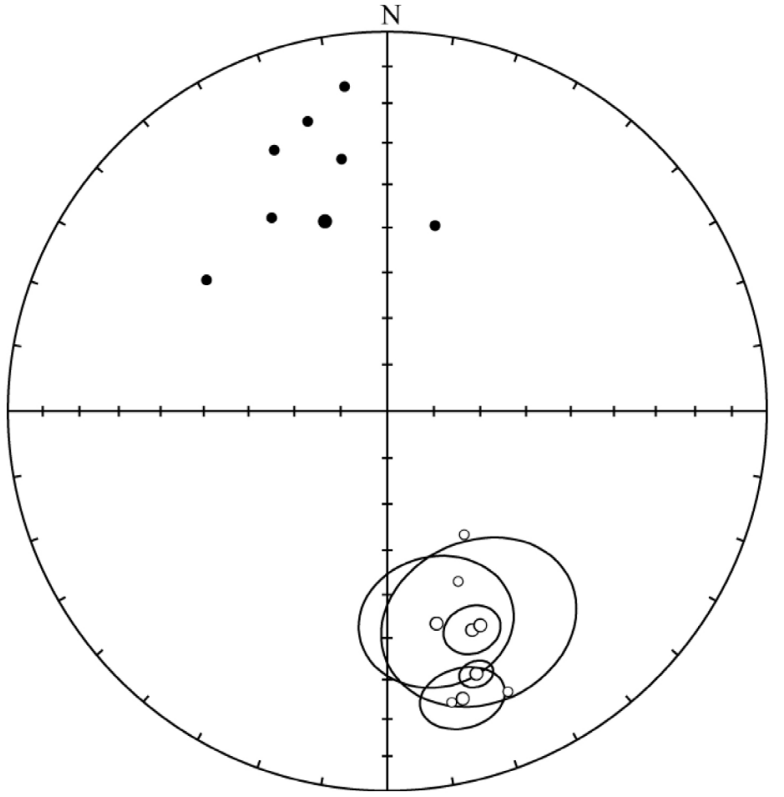

Figura 16. Direcciones paleomagnéticas medias de unidades del Campo Volcánico de San Luis Potosí en una proyección estereográfica. Los datos se enlistan en la Tabla 3. Los símbolos pequeños corresponden a unidades cuya dirección se basa en solamente un sitio.

Andreani (2008) propuso que los datos paleomagnéticos para la Mesa Central, en el CVSLP y la sierra de Guanajuato apoyan la hipótesis de deformación transtensional asociada al sistema de fallas San Luis-Tepehuanes (SLT), que inicia en la parte sur del CVSLP y se extiende al NW cruzando

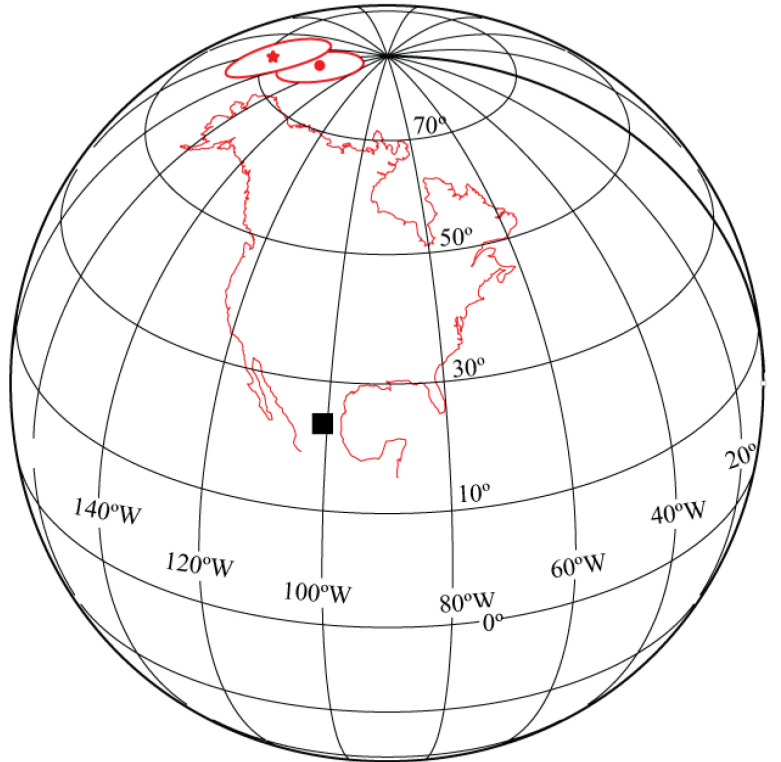

Figura 17. Posición del paleopolos de referencia (círculo) para 30 Ma, así como el paleopolo del CVSLP calculado en el presente estudio (estrella). También se indican los conos de confianza al 95\%. El área de estudio se señala con un cuadro cerca del centro de México.

la Sierra de Zacatecas y alcanzando el estado de Durango (Nieto-Samaniego et al., 2005). El sistema SLT es un arreglo regional de fallas con un rumbo general N50W, y la actividad en el sistema fue contemporánea al menos en parte con la actividad ignimbrítica en el CVSLP. Andreani 
(2008) sugiere que rotaciones antihorarias determinadas paleomagnéticamente en rocas del Oligoceno se pueden interpretar en términos de rotaciones con respecto a un eje vertical asociado a cizalla lateral izquierda. Sin embargo, el análisis de los datos paleomagnéticos de Andreani (2008) incluye sitios individuales en la misma unidad de enfriamiento como lecturas independientes del campo geomagético, y parece sobrestimar ligeramente la cantidad de rotación $\left(\sim 10^{\circ}\right)$. En contraste con la interpretación de Andreani, un estudio detallado de fallas en el sistema SLT al oriente del área de estudio (Loza-Aguirre et al., 2008) concluye que no hay evidencia de desplazamiento lateral izquierdo en el sistema

\section{Conclusiones}

Se realizó un muestreo paleomagnético en diferentes zonas del CVSLP, dentro de la Mesa Central, en la unidad litoestratigráfica cartografiada históricamente como Ignimbrita Panalillo Superior. Se colectaron muestras en 52 sitios paleomagnéticos distribuidos en cinco zonas definidas principalmente por la distribución geográfica y el comportamiento estructural. En 32 sitios se lograron determinar direcciones características confiables. La polaridad de todos los sitios muestreados en esta unidad corresponde a un campo magnético reverso.

De los estudios de propiedades magnéticas se puede concluir que la magnetización reside principalmente en magnetita, titanomagnetita con contenido de bajo a intermedio de Ti, y hematita (o maghemita) en menor proporción. Los dominios de los granos ferromagnéticos dominantes son una mezcla de dominios pseudosencillos, con partículas con dominio múltiple y en menor proporción partículas de dominio sencillo, que son capaces de preservar una magnetización característica por periodos de tiempo geológico. Así mismo, los estudios sugieren que una magnetización secundaria fue causada principalmente por rayos (MRI).

De los análisis paleomagnético y geocronológico realizados en las diferentes zonas se concluye que existe una diferencia significativa en las direcciones obtenidas y en la edad en la zona La Pendencia con respecto a otras zonas. La diferencia en direcciones es en inclinación, por lo que no se puede explicar en términos de rotaciones tectónicas. Así, el muestreo permite determinar dos polos paleomagnéticos virtuales para la Ignimbrita Panalillo.

De los fechamientos radiométricos se puede argumentar que la unidad litoestratigráfica no es una ignimbrita formada en una sola erupción volcánica. Se interpretan dos eventos diferentes que produjeron rocas con características litológicas similares en diferentes episodios: a los 26.5 en el área de La Pendencia y a los 28.1 Ma en la mayoría de las otras zonas estudiadas. Es posible que un evento anterior haya ocurrido a los $31 \mathrm{Ma}$ en la zona de Mexquitic. El intervalo definido por los fechamientos incluye la serie de crones de $\mathrm{C} 12 \mathrm{r}$ a C6Br, pero la interpretación más armónica es atribuir un evento al cron C8r (de 26.55 a $27.027 \mathrm{Ma}$ ) y otro en el cron C9r (27.9 a 28.3 Ma).

Se determinó un polo paleomagnético para el CVSLP basado en 17 polos virtuales que es concordante respecto al polo de Norteamérica, con valores de $\mathrm{R}=-7.9^{\circ} \pm 9.6^{\circ} \mathrm{y}$ $\mathrm{F}=-8.0 \pm 11.6$ que no son estadísticamente significativos. Es posible explicar parcialmente la rotación aparente en términos de dos eventos de fallamiento (acompañados de basculamientos).

El hecho de que el cálculo de la rotación no sea estadísticamente significativo, no necesariamente implica que no hubiese ocurrido una rotación $<10^{\circ}$ en el sentido contrario a las manecillas del reloj como han sugerido otros autores. Existen modelos en que esta rotación ha sido explicada como el producto del movimiento lateral izquierdo de la reactivación de las fallas NW-SE del área durante el retroceso de la placa oceánica (roll-back), que habría generado el fallamiento normal en sentido NW-SE. Sin embargo, desde el punto de vista paleomagnético, por ahora es más sencillo explicar la discordancia en declinación como una rotación aparente.

\section{Agradecimientos}

Este trabajo fue posible realizarlo bajo el apoyo de una beca de doctorado para el primer autor por el CONACYT, con no. 179803 al igual que con recursos de los proyectos de investigación 47041 y 129550 a J. Aranda-Gómez. Iriondo agradece a Mick Kunk y Ryan McAleer del Laboratorio de Termocronología Ar-Ar del U.S. Geological Survey en Reston, Virginia, por su ayuda en la obtención de los datos Ar-Ar presentados en este trabajo. Agradecemos a Mónica Enríquez del CGEO por ayudarnos en la separación mineral de los sanidinos para los estudios de Ar-Ar. El primer autor agradece al Dr. Emilio Herrero Bervera por acceso al laboratorio de la Universidad de Hawai, al Dr. Harald Böhnel por el apoyo entre otras cosas en la obtención de las curvas de histéresis en el GeoForschungsZentrum, en Potsdam, Alemania, a la Dra. Marina Vega González por el apoyo en el uso del SEM., y a Juan Tomás Vázquez por la elaboración de láminas delgadas. Agradecemos también la revisión crítica y sugerencias hechas por L. Alva Valdivia, G. Labarthe y M. Franco-Rubio al manuscrito original.

\section{Referencias}

Aguirre-Díaz, G.J., Labarthe-Hernández, G., 2003, Fissure ignimbrites: Fissure source origin for voluminous ignimbrites of the Sierra Madre Occidental and its relationship with Basin and Range faulting. Geology, 31, 773-776.

Aguirre-Díaz, G.J., McDowell, F., 1993, Nature and timing of faulting and synextensional magmatism in the southern Basin and Range, central-eastern Durango, Mexico: Geological Society of America Bulletin, 105, 1435-1444. 
Alexander, E.C.Jr., Mickelson, G.M., Lanphere, M.A., 1978, Mmhb-1: A new ${ }^{40} \mathrm{Ar} /{ }^{39} \mathrm{Ar}$ dating standard, en Zartman, R.E., (ed.), Short papers of the fourth international conference, geochronology, cosmochronology, and isotope geology: U.S. Geological Survey Open-File Report, 78-701, 6-8.

Andreani, L., 2008, Contraintes structurales et cinématiques sur une frontière de plaque récente: La limite nord du Bloc Sud Mexicain, Tesis Doctoral Université Paul Cézanne Aix Marselle III. Francia, $206 \mathrm{p}$.

Aranda-Gómez, J..J., Molina-Garza, R., McDowell, F.W., Vassallo-Morales L.F., Ortega-Rivera, M.A., Solorio-Munguía1, J.G., AguillónRobles, A., 2007, The relationships between volcanism and extension in the Mesa Central: the case of Pinos, Zacatecas, Mexico: Revista Mexicana de Ciencias Geológicas, 24, 216-233.

Bellon, H., Quoc Buü, N., Chaumont, J., Philippet, J.C., 1981, Implantation ionique d'argon dans une cible support: application au traçage isotopique de l'argon contenu dans les minéraux etles roches: C.R. Académie des Science de Paris, 292, 977-980.

Besse J., Courtillot V., 2002, Apparent and true polar wander and the geometry of the geomagnetic field in the last 200 million years: Journal of Geophysical Research, 107, doi:10.1029/2000JB000050.

Bobier, C., Robin, C., 1982, Paleomagnetisme de la Sierra Madre Occidental dans les Etats de Durango et Sinaloa (Mexique) Variations du champ ou rotations de blocs au Paléocène et an Néogene?: Geofisica Internacional, 21, 57-86.

Butler, R.F., 1998, Paleomagnetism: Magnetic Domains to Geologic Terranes. Electronic Edition, University of Arizona, Departament of Geosciencies, Tucson, AZ, USA. 238 p.

Cande, S.C., D.V. Kent, 1995, Revised calibration of the geomagnetic polarity time scale for the Late Cretaceous and Cenozoic: Journal of Geophysical Research, 100, 6093-6095.

Cebula, G.T., Kunk, M.J., Mehnert, H.H., Naeser, C.W., Obradovich, J.D., Sutter, J.F., 1986, The Fish Canyon Tuff: A potential standard for the ${ }^{40} \mathrm{Ar} /{ }^{39} \mathrm{Ar}$ and fission track dating methods: Terra Cognita, 6(2), 139-140.

Cox A. and Dalrymple G.B., 1967, Statistical analysis of geomagnetic reversal data and the precision of potassium-argon dating. Journal of Geophysical Research, 72, 2603-2614.

Dalrymple, G.B., Alexander, E.C., Lanphere, M.A., Kraker, G.P., 1981, Irradiation of samples for ${ }^{40} \mathrm{Ar} /{ }^{39} \mathrm{Ar}$ dating using the Geological Survey TRIGA reactor: U.S. Geological Survey Professional Paper $1176,55$.

Day, R., Fuller, M., Schmidt, V.A., 1977, Hysteresis properties of titanomagnetites: grain-size and compositional dependence, Physics of the Earth and Planetary Interiors, 13, 260-267.

Deino, A. L., 2001, Users manual for Mass Spec 5.02: Berkeley Geochronology Center Special Publication 1a, 119

Dunlop, D.J. Özdemir, O., 1997, Rock Magnetism: Fundamentals and Frontiers: Cambridge University Press, Cambridge, UK, 537 p.

Fisher, R.A., 1953, Dispersion on a sphere, Proceedings of the Royal Society A, 217, 295-305.

Goguitchaichvili, A., Alva-Valdivia L.M., Urrutia-Fucugauchi J., 2001, Paleomagnetic and paleointensity study of Oligocene volcanic rocks from Chihuahua (northern Mexico): Physics of The Earth and Planetary Interiors, 124, 223-236.

Iriondo, A., Kunk, M.J., Winick, J.A., Consejo de Recursos Minerales, $2003,{ }^{40} \mathrm{Ar} /{ }^{39} \mathrm{Ar}$ dating studies of minerals and rocks in various areas in Mexico: USGS/CRM Scientific Collaboration (Part I): U.S. Geological Survey Open File Report, OF-03-020, 79 p.

Iriondo, A., Kunk, M.J., Winick, J.A., Consejo de Recursos Minerales, $2004,{ }^{40} \mathrm{Ar} /{ }^{39} \mathrm{Ar}$ dating studies of minerals and rocks in various areas in Mexico: USGS/CRM Scientific Collaboration (Part II): U.S. Geological Survey Open File Report, OF-04-1444, 46 p.

Kirschvink, J.L., 1980, The least-squares line and plane and the analysis of paleomagnetic data: examples from Siberia and Morroco, Geophysical Journal of the Royal Astronomical Society, 62, 699-718.

Kunk, M.J., Sutter, J.F., Naeser, C.W., 1985, High-precision ${ }^{40} \mathrm{Ar} /{ }^{39} \mathrm{Ar}$ Ages of Sanidine, Biotite, Hornblende, and Plagioclase from the
Fish Canyon Tuff, San Juan Volcanic Field, South-central Colorado: Geological Society of America Abstracts with Programs, 17, 636.

Labarthe-Hernández, G., Tristán-González, M., 1978, Cartografía Geológica Hoja San Luís Potosí: Universidad Autónoma de San Luís Potosí: Instituto de Geología y Metalurgia, Folleto Técnico 59, 41.

Labarthe-Hernández, G., Tristán-González, M., Aranda-Gómez, J. J., 1982, Revisión estratigráfica del Cenozoico de la parte central del Estado de San Luís Potosí: Universidad Autónoma de San Luís Potosí, Instituto de Geología y Metalurgia, Folleto Técnico, 85, 208.

Loza-Aguirre, I., Nieto-Samaniego, A.F., Alaniz-Álvarez, S., Iriondo, A., 2008, Relaciones estratigráfico-estructurales en la intersección del sistema de fallas San Luis-Tepehuanes y el graben de Aguascalientes, Mexico central: Revista Mexicana de Ciencias Geológicas, 25, 533-548.

MacDonald, W.D., 1980, Net Tectonic Rotation, Apparent Tectonic Rotation, and the Structural Tilt Correction in Paleomagnetic Studies: Journal of Geophysical Research, 85, 3659-3669.

McFadden, P. L., McElhinny, M.W., 1990, Classification of the reversal test in palaeomagnetism: Geophysical Journal International, 103, 725- 729.

Nieto-Samaniego, A.F., Alaniz Alvarez, S.A., Camprubi Cano, A., 2005, La Mesa Central de México: estratigrafía, estructura y evolución tectónica cenozoica: Boletín de la Sociedad Geológica Mexicana, 57, 85-317.

Orozco-Esquivel, M.T., Nieto-Samaniego, Á.F., Alaniz-Álvarez, S.A., 2002, Origin of rhyolitic lavas in the Mesa Central, Mexico, by crustal melting related to extension: Journal of Volcanology and Geothermal Research, 118, 37-56.

Snee, L.W., Sutter, J.F., Kelly, W.C., 1988, Thermochronology of economic mineral deposits; dating the stages of mineralization at Panasqueira, Portugal, by high-precision ${ }^{40 / 39}$ Ar age spectrum techniques on muscovite: Economic Geology, 83, 335-354.

Steiger, R.H., Jäger, E., 1977, Subcommission on geocrhronology: convention on the use of decay constants in geo- and cosmochronology: Earth and Planetary Science Letters, 36, 359-362.

Tauxe, L., Mullender, T.A.T., Pick, T., 1996, Potbellies, wasp-waist, and superparamagnetism in magnetic hysteresis: Journal of Geophysical Research, 101(B1), 571-583.

Torres-Hernández, J.R., 2009, Origen y emplazamiento de las ignimbritas Cantera y Panalillo del campo volcánico de San Luis Potosí, Tesis doctoral, Posgrado en Ciencias de la Tierra: Universidad Nacional Autónoma de México, Mexico D.F., 204p.

Torres-Hernández, J.R., Labarthe-Hernández, G., Aguillón-Robles, A., Gómez- Anguiano, M., Mata-Segura, J.L., 2006, The pyroclastic dikes of the Tertiary San Luis Potosi volcanic field: Implications on the emplacement of Panalillo ignimbrite: Geofísica Internacional, 45, 243-253.

Tristán-González, M., 2008, Evolución Tectono-Volcánica durante el paleógeno en la porción sur oriental de la Mesa Central: Posgrado en Ciencias de la Tierra, Universidad Nacional Autónoma de México, Mexico D.F., 204 p., Tesis doctoral.

Tristán-González, M., Aguillón-Robles, A., Barboza-Gudiño, R., TorresHernández, J. R., Bellon, H., López-Doncel, A., Rodríguez-Rios, R., Labarthe-Hernández, G., 2009, Geocronología y distribución espacial del vulcanismo del Campo Volcánico de San Luis Potosí: Boletín de la Sociedad Geológica Mexicana, 61, 287-303.

Tristán-González, M., Labarthe-Hernández, G., Aguirre-Díaz, G., Aguillón-Robles, A., 2008, Tectono-volcanic control of fissure type vents for the $28 \mathrm{Ma}$ Panalillo Ignimbrite in the Villa de Reyes graben, San Luís Potosí, México: Collapse Calderas Workshop. México, IOP Conf. Series: Earth and Environmental Science 3 (2008) 012026 doi:10.1088/1755-1307/3/1/012026.

Urrutia-Fucugauchi, J., 1981, Paleomagnetic evidence for tectonic rotation of northern Mexico and the continuity of the Cordilleran orogenic belt between Nevada and Chihuahua: Geology, 9, 178-183.

Xu, S. S., Nieto-Samaniego, Á.F., Alaniz-Álvarez, S. A., 2004, Vertical shear mechanism of faulting and estimation of strain in the Sierra de San Miguelito, Mesa Central, Mexico: Geological Acta, 2, 189-201. 
Zijderveld, J.D.A., 1967, A.C. demagnetization of rocks: Analysis Results, en Collinson, D.W., Cree. K.M. Runcorn, S.K., (eds.), Methods in Paleomagnetism: Elsevier, Amsterdam, 251-286.

\section{Apéndice}

- $\mathrm{Ar}^{40} / \mathrm{Ar}^{39}$ en sanidinos con láser

Cristales únicos de sanidino de la ignimbrita Panalillo Superior de diferentes localidades fueron separados en el laboratorio de Separación Mineral del Centro de Geociencias-UNAM en Juriquilla, Querétaro, utilizando técnicas convencionales de separación magnética y líquidos pesados. Aproximadamente $10 \mathrm{mg}$ por muestra de estos cristales fueron irradiados, es decir, expuestos a un campo de neutrones por 20 horas (paquete de irradiación KD48 en cápsulas de aluminio) en la parte central del reactor nuclear tipo TRIGA ubicado en el U.S. Geological Survey de Denver, Colorado. El mineral monitor utilizado para controlar la dosis neutrónica en el paquete de irradiación fue el sanidino de la toba Fish Canyon (FCT-3) con una edad de 27.79 Ma (Kunk et al., 1985; Cebula et al., 1986) con respecto a la muestra monitor Mmhb-1 (hornblenda) con una edad K-Ar de $519.4 \pm 2.5 \mathrm{Ma}$ (Alexander et al., 1978; Dalrymple et al., 1981). Detalles sobre el procedimiento de irradiación, el tipo de contenedor y la geometría de las muestras, están descritos en detalle en Snee et al. (1988). Para información adicional sobre estas técnicas analíticas, se refiere al lector a las publicaciones de Iriondo et al. (2003, 2004). Los datos isotópicos de los experimentos de fusión total (Tabla 2) fueron reducidos y graficados (Figura 13) con el programa de computación Mass Spec desarrollado por Deino (2001). Por último, cabe mencionarse que en la reducción de datos se emplearon las constantes de desintegración recomendadas por Steiger y Jäeger (1977).
Manuscrito recibido: Agosto 9, 2010.

Manuscrito corregido recibido: Octubre 7, 2010.

Manuscrito aceptado: Enero 19, 2011.

$\cdot \mathrm{K} / \mathrm{Ar}$

Los análisis de K/Ar se realizaron en separados de feldespato (sanidinos), los cuales fueron obtenidos en el laboratorio de Separación Mineral del Centro de Geociencias-UNAM en Juriquilla, Querétaro, utilizando técnicas convencionales de separación. Estos separados fueron enviados al Laboratorio de Geocronología de la Universidad de Bretaña Occidental en Francia, donde los minerales con tamaños de 0.30 a $0.15 \mathrm{~mm}$ fueron lavados con agua destilada y posteriormente usados en alguno de los siguientes análisis: (i) una cantidad exacta fue pulverizada en un mortero de ágata para realizar análisis de $\mathrm{K}$ por absorción atómica después de haber sido atacado químicamente con ácido fluorhídrico. (ii) Granos de sanidino fueron usados para realizar mediciones de relaciones isotópicas de argón. La extracción de argón fue realizada al alto vacío por inducción de calor con un crisol de molibdeno. Los gases extraídos fueron limpiados en dos hornos de esponjas de titanio y finalmente purificados utilizando dos colectores SAES de Al-Zr. La composición del Ar isotópico y las concentraciones de ${ }^{40} \mathrm{Ar}$ fueron medidas usando un espectrómetro de masas de acero inoxidable de $180^{\circ}$ equipado con un amplificador Keithler 643. El método de dilusión isotrópica fue aplicado usando un Spike de ${ }^{38} \mathrm{Ar}$ enterrado como iones en recipientes de aluminio, siguiendo el procedimiento descrito por Bellon et al. (1981). Las edades fueron calculadas usando las constantes recomendadas por Steiger y Jäger (1977) y los errores de \pm 1 ơ se calcularon usando las ecuaciones de Cox y Dalrymple (1967). 